\title{
A morphometric analysis of prognathism and evaluation of the gnathic index in modern humans
}

\author{
K.M. Lesciotto ${ }^{1 *}$, L.L. Cabo ${ }^{1}$, H.M. Garvin ${ }^{1,2}$ \\ ${ }^{1}$ Department of Applied Forensic Sciences, Mercyhurst University, 501 E. $38^{\text {th }}$ Street, Erie, PA \\ 16546, USA \\ ${ }^{2}$ Department of Anthropology/Archaeology, Mercyhurst University, 501 E. $38^{\text {th }}$ Street, Erie, PA \\ 16546, USA
}

Received 31 August 2016, accepted 17 April 2016

*Corresponding author. Tel.: + 1-847-890-2803. Email address: kmlesciotto@gmail.com (Kate M. Lesciotto) 


\begin{abstract}
Subnasal prognathism is a morphological feature often described in studies of paleoanthropology, bioarchaeology, and forensic anthropology. This trait is commonly quantified using the gnathic index, which compares basion-prosthion and basion-nasion lengths. This study used geometric morphometrics to assess whether the gnathic index is a reliable indicator of subnasal prognathism and to explore the effects of sex, population, and allometry on this trait. Nineteen craniofacial landmarks were collected from three-dimensional cranial surface scans of 192 individuals across five population groups. Generalized Procrustes analysis and principal components analysis were employed to identify shape components related to changes in subnasal prognathism, comparing component scores to gnathic index values. M/ANOVAs were used to determine the effects of sex and population on prognathism, and linear regression served to assess static allometry. The gnathic index was significantly correlated with PCs 1 and 3, which appeared to capture prognathic shape change, but also with PCs 2 and 6, which reflected other craniofacial shape changes. Population differences in levels of prognathism were identified, but no significant effects of sex or allometry were found. The results show that, although the gnathic index correlates with prognathic shape variation, it is also influenced by other variables, such as the relative position of basion. In this sense, the gnathic index serves to illustrate the shortcomings of linear measurement analysis as compared to landmark configurations. Further, the results demonstrate that subnasal prognathism is a complex feature in need of redefinition.
\end{abstract}

\title{
Introduction
}

When discussing prognathism, it is important to distinguish it from midfacial projection (Hanihara, 2000; Lieberman et al., 2000; Lieberman, 2011). Midfacial, or facial, projection has been defined as the "degree to which [the] face projects in front of [the] cranial base" (Lieberman et al., 2000:118). In contrast, prognathism, which may be referred to as lower facial, subnasal, or maxillary alveolar prognathism, is defined as the anterior projection of the lower face relative to the upper face (Lieberman, 2011; Neaux et al., 2013). This is also distinct from mandibular prognathism, which may be referred to as basal prognathism, and is more often 
discussed in clinical literature (Björk, 1950; Chang et al., 2006). For the purposes of this paper, "prognathism" will refer strictly to subnasal maxillary alveolar projection (i.e., subnasal prognathism).

Prognathism is frequently invoked to characterize and distinguish hominin taxa and human populations, at the paleontological, bioarchaeological, and forensic levels (Bass, 1987; Brooks et al., 1990; Brown and Maeda, 2004; Gonzalez-Jose et al., 2007; Kennedy and Posseh1, 2012; Lieberman, 2011; Martínez-Abadías et al., 2006; Ousley et al., 2009; Quatrehomme et al., 2007; Spoor et al., 2005; Weisensee and Jantz, 2011). Varying degrees of prognathism have been identified as distinguishing features between both temporally and geographically distinct human populations (e.g., Brown and Maeda, 2004; Gonzalez-Jose et al., 2007) and as an indicator of gene flow between populations (Gonzalez-Jose et al., 2007; Martínez-Abadías et al., 2006). Among modern humans, populations of African ancestries are generally characterized as displaying a high-degree of subnasal prognathism (i.e., prognathic), in contrast with those of European, Asian, and Native American ancestries, who are generally described as having little to no prognathism (i.e., orthognathic) (Bass, 1987; Gill and Rhine, 1990).

Subnasal prognathism and associated nasal and palate morphology have also been described as sexually dimorphic characteristics (Bigoni et al., 2010; Franklin et al., 2006). In addition, differences in subnasal prognathism have been argued to be driven, in part, by variation in overall size (Franklin et al., 2006; Weisensee and Jantz, 2011). However, despite recurrent mentions in studies of overall craniofacial morphology, few studies have focused on the specific morphology contributing to subnasal prognathism. This may in part be due to difficulties with objectively evaluating this trait and a lack of understanding regarding the developmental processes involved in the expression of prognathism.

Throughout paleoanthropology, bioarcheology, and forensic anthropology, subnasal prognathism is commonly described qualitatively, as a relative degree of prognathism (e.g., high, moderate, low, or lacking) compared to a reference group or groups (e.g., Gill and Rhine, 1990). However, such qualitative descriptions are highly subjective, with high intra- and inter-observer error rates (L'Abbé et al., 2011), and are hard to validate statistically. There have been several attempts in the past to quantify subnasal prognathism metrically. Huxley (1863) suggested using the craniofacial, or sphenomaxillary, angle as a measure of prognathism. This angle was calculated from lines connecting prosthion (the most anterior point on the maxilla), sellion (the 
most anterior point on the sphenoid), and basion (the most anterior point on the foramen magnum). The use of sellion, however, requires endocranial access or a lateral radiographic examination, thereby making this method difficult to apply to intact crania. To overcome this issue, the use of the "gnathic index" was proposed, using three ectocranial landmarks: basion, nasion, and prosthion (Martin, 1957; Martin and Knussmann, 1988).

The gnathic index is calculated as a ratio of basion-prosthion length to basion-nasion length (Fig. 1) and has continued to be used among bioarchaeologists, skeletal biomechanists, forensic anthropologists, and paleoanthropologists to document and analyze subnasal prognathism (Brooks et al., 1990; Brown, 2012; Brown and Maeda, 2004; Hershkovitz and Galili, 1991; Hershkovitz et al., 1995; Kennedy and Possehl, 2012; Liebenberg et al., 2015; Orish and Ibeachu, 2016; Patriquin, 2013; van Rensburg et al., 2012). For example, Brown (2012) recently used the gnathic index to assert that the level of prognathism seen in the LB1 hominin specimen from Flores does not overlap with the range of indices seen in modern human myxoedematous endemic cretins. Brown and Maeda (2004) compared the general decrease in orofacial robusticity, as reflected by the gnathic index, occurring after the Neolithic period to changes in orbital size and shape. Further, it is common to report the gnathic index when describing or comparing bioarchaeological remains or hominin fossil finds (Douglas et al., 1997; Hanihara, 2000; Pietrusewsky and Douglas, 1992; Thorne and Wolpoff, 1981; Wu et al., 2007). Once calculated, the gnathic index score is placed into one of three possible categories: orthognathic individuals with an index of less than 98, mesognathic individuals with an index of 98-103, and prognathic individuals with an index greater than 103 (Martin, 1957; Martin and Knussmann, 1988). The apparent simplicity of the gnathic index makes it an attractive tool; basion-prosthion and basion-nasion are standard cranial measurements that can be taken with a common set of spreading calipers, and the index is thought to reflect the anterior projection of prosthion away from the rest of the facial skeleton.

\section{INSERT Fig. 1 ABOUT HERE}

Advances in geometric morphometric techniques provide more precise and powerful tools to objectively quantify and statistically analyze shape changes that traditional osteometric landmark measurements and analysis may not be able to capture. Numerous studies have applied geometric 
morphometric techniques to craniofacial morphological variation (Bigoni et al., 2010; Bruner and Manzi, 2004; Hennessy and Stringer, 2002; Martínez-Abadías et al., 2006; Rosas and Bastir, 2002). Although many of these studies describe prognathism as contributing to morphological differences between populations, they do not focus specifically on the shape changes that define and contribute to prognathism itself.

No previous studies have examined whether the gnathic index directly reflects actual patterns of prognathic morphological variation. This includes a lack of reliable assessments of whether the gnathic index successfully describes these shape variations and therefore provides an appropriate measurement of prognathism. Further, indices and ratios present well-known statistical and geometric problems, including violations of the assumption of isometry, the loss of relevant geometric information, and the potential to mislead due to the reduction of complex biological variation to a one-dimensional form (Green and Chapman, 2011; Franks and Cabo, 2014; Liebenberg et al., 2015). Thus, the first goal of this study is to quantify changes in prognathic variation from a set of three-dimensional (3D) craniofacial landmarks and compare the resulting morphometric characterization of this character to that provided by the gnathic index. If the gnathic index is a reliable indicator of subnasal prognathism, then the morphometric shape components capturing this trait should be highly correlated with the gnathic index. Similarly, if the gnathic index is an appropriate measurement of prognathism, it should not be strongly influenced by other unrelated factors (i.e., it should not correlate with shape components that are independent from prognathism). Additionally, the morphometric analysis will provide a foundation to evaluate the differences in prognathism between sexes and across populations, including any allometric effects of size on prognathic shape.

\section{Materials and methods}

In order to capture the full range of prognathic shape changes, a set of nineteen craniofacial landmarks were chosen for this study (Table 1; Fig. 2). Five of the landmarks were located in the mid-sagittal plane, and the remaining seven were paired and collected bilaterally. The majority of these landmarks have been well defined in the literature (Buikstra and Ubelaker, 1994; Howells, 1973), with the exception of the bilateral posterior alveolar points for the canines and second maxillary molars. Similar points have been used in at least one prior study (Spoor et al., 2005), and these canine and maxillary points were used in order to capture potential shape 
changes occurring in both the length and width of the palate. In accordance with the commonly accepted definition of subnasal prognathism, landmarks on both the lower face (e.g. prosthion, inferior nasal aperture) and upper face (e.g. dacryon, frontomalare temporale) were chosen for analysis. Landmark data for bregma were also collected, as preliminary research and evaluation suggested that the relative vertical position of basion could have an effect on the gnathic index.

\section{INSERT Fig. 2 AND Table 1 ABOUT HERE}

This study used an existing dataset of 3D surface scans of adult human crania that were collected using a NextEngine Desktop Scanner (model 2020i). The method and details of the scanning protocol for this dataset are described in Garvin and Ruff (2012). Scans of crania that did not present all nineteen of the pre-defined landmarks, as well as those that had insufficient dentition or worn alveolar processes preventing an accurate estimation of prosthion or the posterior canine and posterior second maxillary molar landmarks, were excluded from the study. Individual crania with autopsy cuts that could be reliably reconstructed were included in the sample. Their calottes were reconstructed by one of the authors (HMG) using wax, taking into account bone loss from the use of a saw and making sure to maintain a continuous arc between the two cranial portions. In order to examine the range of prognathism in modern humans, the sample included adult males and females from multiple populations and several skeletal collections. The final sample comprised 192 individuals representing six different skeletal samples: (1) U.S. Whites from the William M. Bass Donated Skeletal Collection, University of Tennessee, (2) U.S. Blacks from the Hamann-Todd Osteological Collection, Cleveland Museum of Natural History, (3) U.S. Blacks and U.S. Whites from the Robert J. Terry Anatomical Skeletal Collection, Smithsonian Institution National Museum of Natural History, (4) Kulubnarti Medieval Nubians curated at the University of Colorado, (5) Arikara Native Americans curated at the University of Tennessee, and (6) Portuguese from the Luis Lopes Collection, Bocage Museum. These groups were selected for study as they represent both a geographically and temporally diverse sample and incorporate a significant degree of human variation, thus reflecting the varying degree of prognathism among human groups. For the purposes of this study, samples were pooled into five broader population groups: U.S. White (Bass and Terry), U.S. Black (Hamann-Todd and Terry), Nubian, Native American, and Portuguese (Table 2). 


\section{INSERT Table 2 ABOUT HERE}

Ancestry is known for all skeletal samples, and sex is positively known for all except the archaeological samples (Kulubnarti and Arikara). The archaeological specimens were sexed using associated pelvic material and traditional osteological techniques (Bruzek, 2002; Phenice, 1969) by one of the authors (HMG). Sex estimates were then compared to those provided by the excavators/original researchers. Original sex classifications assigned to the Arikara sample took into account burial artifacts (Owsley and Bass, 1979; Owsley and Jantz, 1994). For the Kulubnarti sample, many of the original assigned sexes were based on mummified soft tissue (Turner et al., 2007). Those without any soft tissue preservation were assigned a sex after examining both cranial and pelvic traits (Turner et al., 2007). Prior study of known-sex individuals from the Kulubnarti sample has suggested only a minimal possibility of misclassification of sex, due to non-overlapping pelvic morphology (Sibley et al., 1992). Only individuals that displayed consistent sex assignments (by HMG and original researchers) were included in this study.

Three-dimensional coordinates for nineteen landmarks were collected for each individual using Geomagic Studio software (Raindrop Geomagic, Research Triangle Park, NC). The accuracy of 3D surface scan data collected using a NextEngine scanner has been validated in a number of studies (Aguilar et al., 2009; Sholts et al., 2010; Sholts et al., 2011). In addition, studies have consistently demonstrated the high degree of precision when taking indirect measurements from 3D laser surface scans as compared to direct measurements by traditional anthropometry techniques (Fourie et al., 2011; Richard et al., 2014; Sholts et al., 2011). To calculate the gnathic index, the basion-prosthion and basion-nasion lengths were calculated from the corresponding $\mathrm{x}, \mathrm{y}$, and $\mathrm{z}$ coordinates according to the following equation:

$$
\text { Distance }=(x 2-x 1) 2+(y 2-y 1) 2+(z 2-z 1) 2
$$

The gnathic index was then calculated as:

basion-prosthion lengthbasion-nasion length $\times 100=$ Gnathic Index

Using Morphologika (O’Higgins and Jones, 2006), a generalized Procrustes analysis (GPA) was run. In the GPA analysis, all of the specimens were aligned and oriented by minimizing the 
sum of the squared distances between homologous points among specimens (Zelditch et al., 2004). A principal component analysis (based on the variance/covariance matrix) was then performed on the resultant Procrustes coordinates. Due to the different modes of visual outputs, both Morphologika and MorphoJ (Klingenberg, 2011) were used to visualize and define the relative shape changes captured by the individual principal components (PCs). Morphologika permits the rotation of specimens and live viewing of shape changes as the user traverses the principal component axes. MorphoJ provides static wireframe and lollipop diagrams in three specified axes, focusing attention on the relative movement of each landmark with respect to the remainder of the form. Both programs were used to ensure that the visual interpretation of subnasal prognathism was based on a comprehensive set of analyses. While visual interpretations of morphological traits have the potential for subjective error, the lack of objective methods for the quantification of subnasal prognathism for intact, dry crania, aside from the gnathic index being tested, required reliance on visual methods.

A two-factor MANOVA was performed on the pooled sample using all PCs, serving to assess the influence of sex and population on overall cranial shape. Post hoc Tukey's tests were run to identify statistically significant pairwise group differences among population groups. Only those PCs that explained at least five percent of the total shape variance were visually interpreted and used in subsequent univariate analyses. Two-factor ANOVAs were performed on the pooled sample to test for sex and population effects on these individual PCs. Based on the visual interpretations, it was noted whether the observed PC shape changes appeared to reflect changes in subnasal prognathism. In addition, the original 3D cranial scans of individuals falling at the extremes of each PC axis were consulted to confirm that the shape changes interpreted from the wireframes were indicative of true shape variations. Spearman's rank correlation tests on the pooled sample served to determine whether the gnathic index was correlated with any of the individual PCs. Finally, to assess the effect of allometry on prognathism, linear regression tests were run between centroid size and PC scores for the pooled sample, as well as all sex and population subgroups. All hypothesis tests were run in SPSS 22.0 (IBM SPSS, Chicago, IL).

\section{Results}

\section{Evaluation of the Gnathic Index}


Population averages and standard deviations for basion-prosthion length, basion-nasion length, and the gnathic index are presented in Table 3. The principal component analysis returned a total of fifty PCs. Univariate analyses were restricted to the first six PCs, each of which individually accounted for more than five percent of the variance (cumulatively accounting for $55 \%$ of the total variance) (Table 4 ).

\section{INSERT Table 3 AND Table 4 ABOUT HERE}

The Morphologika wireframes for the first six PCs are presented in Figure 3, and the interpreted prognathic shape changes are presented in Table 4. Given the lack of objective methods for quantifying subnasal prognathism on dry crania, aside from the gnathic index, these wireframes were visually interpreted and categorized as yes/no for the presence of prognathic shape changes. For the initial visual interpretation (Fig. 3), the wireframes for the extreme positive values for each PC were compared to the wireframes for the extreme negative values for each PC, in the orientation of the Procrustes analysis output. Focus was directed to any obvious visual indication of subnasal prognathism. When attempting to interpret the shape changes captured by the PCs using this method, some shortcomings to the definition of subnasal prognathism became apparent. Subnasal prognathism is defined as the anterior projection of the lower face relative to the upper face (Lieberman, 2011; Neaux et al., 2013), but it is unclear whether this relative degree of projection is from a single point or a plane, and, in either scenario, the definition fails to specify what landmarks should be used to define the anterior position of the "lower face". If the individual crania are re-oriented in Frankfurt horizontal, variations in the upper facial slope or angle complicate interpretations of subnasal prognathism.

For these reasons, as a secondary attempt to assess and confirm which PCs were contributing to prognathic shape changes, the resultant PCA wireframes were re-oriented so that they were aligned vertically by the nasion and alare points (Fig. 4). In this manner, the anterior projection of the maxilla (as represented by anterior prosthion) could be more specifically evaluated relative to the upper facial plane. This method may appear unconventional, but given the ambiguous definition of subnasal prognathism, the authors felt it may be helpful in the interpretation of the relative shape changes, particularly from the rationale of the gnathic index 
as a measure of the relative projection of basion-prosthion in respect to the length of basionnasion.

\section{INSERT Fig. 3 AND Fig. 4 ABOUT HERE}

Both PCs 1 and 3 were interpreted to capture shape variation related to prognathism and were significantly correlated with the gnathic index (Table 4). PC1, which explains $17.2 \%$ of the total shape variance and appears to capture the main prognathic shape change. As seen in Figure 3, prosthion and the entire maxillary region exhibit an anterior projection relative to the inferior nasal aperture for the positive PC1 values. PC1 explains $36 \%$ of the variance of the gnathic index $(\mathrm{r}=0.604, p<0.01)$. PC3 also captures variation in the degree of prognathism, although in this instance, the anterior projection of the maxilla is relative to the position of staurion, indicating a possible lengthening of the palate (Fig. 3). PC3 was also positively correlated with the gnathic index, although explaining only $15 \%$ of its variance $(\mathrm{r}=0.389, p<0.01)$.

In contrast, the shape variations expressed by PCs 2 and 4-6 did not appear to be related to prognathism. The major shape change observed in PC2 is a shortening of the facial skeleton relative to cranial vault height, in addition to changes in the vertical position of basion. Although PC2 also captures some superior-inferior deflection of prosthion, there is no obvious change in the degree of anterior projection. PC6 captures a slight posterior displacement of nasion relative to alare and the inferior nasal aperture landmarks (Fig. 3). However, both PC2 and PC6 were significantly correlated with the gnathic index (Table 4). PCs 4 and 5 were not investigated further as they neither captured prognathism nor were significantly correlated with the gnathic index.

The gnathic index was further investigated by comparing sets of crania with the same index score. Despite having the same index, multiple pairs of crania were found that had visually different levels of prognathism. Figure 5A displays the crania of two U.S. White males each with an index of 88.9, which falls on the lower end of the scale. Both would be classified as orthognathic based on their gnathic index. Yet, a visual comparison clearly shows significantly more prognathism in the Terry individual. Similarly, Figure 5B compares two individuals with a gnathic index of 95.9, closer to the mesognathic section of the scale, but again with distinctly different levels of prognathism. Finally, Figure 5C is a comparison of two individuals with a 
gnathic index of 103, which falls on the higher end of the scale, and who would both be classified as prognathic. Although both individuals would subjectively be called prognathic, the Terry 615 individual exhibits more subnasal prognathism than the HTH 3131 individual. Thus, the gnathic index appears to be a less reliable indicator of the relative degree of prognathism than previously assumed.

\section{INSERT Fig. 5 ABOUT HERE}

\section{Effects of sex and population}

Two-factor MANOVA testing on the pooled sample of 192 individuals using all 50 PCs demonstrated that both sex and population had a significant effect on shape $(p<0.001)$, although there was no interaction between sex and population $(p=0.369)$ (Table 4). This indicates that levels of sexual differences in craniofacial shape, as measured in this study, do not differ significantly across the population groups considered. The significant effect of population on overall craniofacial shape was expected, given the common perception of differences in prognathism across ancestral groups and the design of the chosen set of craniofacial landmarks to capture prognathic shape changes.

ANOVA tests revealed significant population differences for PCs $1-4$ and $6(p<0.01)$, while only PC5 differed by sex $(p<0.05)$ (Table 5$)$. There was no interaction between sex and population on any of the first six PCs, again suggesting that, in general, levels of sexual dimorphism for craniofacial morphology reflected by the chosen landmarks did not vary across population groups. A summary of the homogenous population subsets obtained from a Tukey's post hoc analysis is presented in Table 6. For PC1, which captures the clearest variation in prognathism, U.S. Whites, Portuguese, and Native Americans grouped together, while U.S. Blacks and Medieval Nubians formed a separate group. Interestingly, the groups formed different subsets in PC3, which appeared to capture a subtler component of prognathism. Native Americans did not differ from either the U.S. Whites group or the U.S. Blacks and Portuguese group, while the Nubian sample was significantly different from all other groups.

\section{INSERT Table 5 AND Table 6 ABOUT HERE}


Figure 6 displays a scatter plot of PC1 and PC3, the two components expressing prognathic shape changes. The U.S. Black and Nubian samples tend to cluster around positive PC1 scores. In contrast, the U.S. White and Portuguese samples cluster around the opposite end of PC1, with primarily negative scores. The Native American sample shows intermediate scores for both PC1 and PC3, occupying a middle ground between European and African ancestries. However, as indicated by the ANOVA results, there is no clustering between sexes.

\section{INSERT Fig. 6 ABOUT HERE}

Figure 7 displays a plot of PC2 and PC6. While neither of these PCs captures prognathic variation, both are nonetheless correlated with the gnathic index. As with PC1 above, U.S. White and Portuguese individuals cluster together for PC2. While these groups tend to exhibit more positive scores, there is more overlap than in PC1. Similarly, the U.S. Black and Nubian samples are more loosely grouped in PC2 than in PC1, although they still cluster together around negative PC2 scores. Examination of the original specimens representing the extremes of the axes confirms the changes previously observed in the vertical position of basion along the PC2 axis. Sex was not significantly correlated with any of these PC scores; accordingly, the plot does not show any clustering of males or females.

\section{INSERT Fig. 7 ABOUT HERE}

\section{Effect of allometry}

The potential influence of allometry on craniofacial morphology was examined by regressing centroid size on the scores for the first six PCs (Table 7). The $r^{2}$ value describes how much of the variance in the PC score can be explained by centroid size; in other words, a significant $\mathrm{r}^{2}$ value indicates that there is an allometric effect on the shape changes captured by that PC. Only the U.S. White female, U.S. White male, and pooled female samples show evidence of allometry with respect to $\mathrm{PC} 3$, which did capture some prognathic variation. $\mathrm{PC} 1$, which captured the main prognathic variation, did not show any evidence of allometry in any of the divided or pooled sex 
and population groups. In contrast, the non-prognathic shape changes captured by PC2 show a significant effect of centroid size for the majority of the individual samples, as well as the pooled sample. Overall, this implies that, while allometry may play a significant role in overall craniofacial morphological variation, it does not seem to explain all the between-group differences detected in prognathism, particularly among male groups.

\section{INSERT Table 7 ABOUT HERE}

\section{Discussion}

Examination of the correlations between the shape differences captured by the first six PCs and the calculated gnathic index indicates that the gnathic index does not adequately reflect subnasal prognathism. Instead, the results of this study indicate that the gnathic index is influenced by relative differences in cranial vault height, defined as basion-bregma diameter (Buikstra and Ubelaker, 1994), and facial height, defined as nasion-prosthion length (Bastir and Rosas, 2004; Buikstra and Ubelaker, 1994), or cranial flexion between the two regions, and thus is not an appropriate measure of prognathism.

Both of the measurements contributing to the gnathic index use basion as one endpoint. However, the relative position of basion with respect to other cranial landmarks has been shown to differ amongst various modern human populations (Lynch et al., 1996). Even minor differences in the vertical position of basion have the potential to alter the relative lengths of basion-prosthion and basion-nasion, in turn altering the gnathic index without any corresponding change in prognathism. This positional influence of basion may have contributed to the results of this study. Interestingly, PCs 2, 3, and 6, which were all correlated with the gnathic index, also captured changes in the vertical position of basion relative to prosthion. It appears that this vertical deflection of basion has a profound impact on the relative lengths of basion-prosthion and basion-nasion, resulting in alterations to the gnathic index that are unrelated to the degree of subnasal prognathism.

Likewise, changes in relative facial height can also directly influence the gnathic index. This can be best interpolated from the principles of basic geometry. The gnathic index is simply a ratio of the lengths of two sides of a triangle (Fig. 1); thus, the index is actually the cosine of the 
angle created between the basion-prosthion and basion-nasion lengths, if the three landmarks formed a right triangle, and will inherently contain information regarding facial height. If this angle remained constant amongst all individuals, then it would provide substantial information regarding the degree of anterior projection of prosthion relative to the upper face. However, this angle is in constant flux between individuals and populations with changes in facial height or relative position of basion, and it is impossible for the gnathic index to distinguish between this variation and actual variation in the degree of prognathism. This is precisely what was noted in relation to $\mathrm{PC} 1$, which captured prognathic shape variation, and PC2, which captured variation in facial height. The gnathic index was correlated with both, as it was unable to parse out the shape changes specific to prognathism. Figure 8 further describes the geometric limitations imposed on the ability of the gnathic index to reflect prognathism. This is in accordance with previous findings that craniofacial orientation may play a significant role in subnasoalveolar morphology among extant hominids (McCollum and Ward, 1997).

\section{INSERT Fig. 8 ABOUT HERE}

Although bregma does not contribute to prognathic shape variation as traditionally defined, it was included in these analyses to: (1) allow the visualization and comparison of changes in cranial vault height and any superior-inferior deflection of basion and (2) form the basionbregma plane and allow the evaluation of the relative degree of anterior projection of the maxilla. However, given its distance from the rest of the craniofacial landmarks chosen for this study, the inclusion of bregma might contribute to produce a potential "Pinocchio effect" (Klingenberg, 2013, and references therein), which must be taken into account for more detailed analyses of prognathism. The algorithm used in GPA to place all forms in a common coordinate system has the effect of reducing the impact of one or two landmarks that show greater variation relative to the other landmarks (Richtsmeier et al., 1992; Slice, 2005; von Cramon-Taudabel et al., 2007; Zelditch et al., 2004). Instead of permitting these localized differences to drastically increase the squared distances between configurations, GPA spreads these differences out across the entire set of landmarks (Slice, 2005). Applied to this study, if this sample of individuals showed great variability in the relative location of bregma, the resulting shapes captured by the subsequent PCA would limit the amount of variation at bregma, but increase the variation spread 
among the remaining landmarks, including those of the lower face that contribute most to the appearance of prognathism. In order to minimize this possibility, the original surface scans were re-examined to confirm the shape changes derived from the Procrustes-transformed Morphologika and MorphoJ wireframes. In addition, for purposes of this study, any potential "Pinocchio effect" would not have affected the finding that individuals with the same gnathic index (derived from the original, non-Procustes 3D coordinates) show clearly different levels of prognathism (Fig. 5).

This study also demonstrates several of the problems with the current definition of subnasal prognathism. As previously mentioned, the definition fails to provide critical information on how this projection is to be judged. Crania are typically viewed in the Frankfurt horizontal position; however, this position does not necessarily align crania according to the axis of the upper face, resulting in potential inconsistencies in judging the relative projection of the lower face between specimens. Aligning crania by the upper facial axis may provide a more consistent view of lower facial projection relative to the upper face, but then the landmarks or planes defining this upper facial axis need to be standardized. Although aligning specimens by such an upper facial axis alleviates some issues by providing a more standardized mean of judging anterior maxillary projection, it may result in the position of some crania varying greatly from normal anatomical orientations. Moreover, such an alignment may overlook differences occurring in individuals with greater or lesser facial slope angles and the contribution of this angle to a prognathic appearance. Without a more precise and objective definition of subnasal prognathism, and the different modes in which it may appear, we are not able to create an accurate and standardized method to quantify this shape change. Even using modern geometric morphometric techniques to visualize prognathic shape differences did not alleviate this problem. The PC wireframes do show prognathic shape variation, but also necessarily incorporate other craniofacial morphological differences, thus complicating their interpretation. Prognathism clearly needs to have a more specific definition, yet such a definition cannot be provided without first understanding the specific morphological changes that are occurring, which likely involve more than one process and path. Further research investigating whether shape changes generally associated with prognathism are occurring in acute craniofacial regions (e.g., palatal changes) or more integrated cranial shape changes (e.g., elongation of the cranial base), is required. Looking at the growth and development of associated craniofacial regions may help shed light on the 
mechanisms involved and the variables affecting prognathism. Once the shape changes occurring with prognathism are more thoroughly understood, further developmental and evolutionary pathways and significance may be extrapolated. This information would be critical in paleoanthropological contexts, where levels of prognathism are often described and used to differentiate hominin taxa.

Beyond the gnathic index, these results contribute to the growing study of craniofacial morphological variation. Multiple studies have reported on the variation of craniofacial traits, and particularly on the use of specific traits to assess the sex of skeletal remains. These metric and nonmetric traits are present across the upper, mid, and lower face, with studies investigating the sexual dimorphism of the glabellar region (Walker, 2008; Williams and Rogers, 2006), browridge (Garvin and Ruff, 2012), zygomatics (Franklin et al. 2006; Spradley and Jantz, 2011; Walrath et al., 2004), and mandible (Walker, 2008; Williams and Rogers 2006). However, less attention has been paid to the particular trait of subnasal prognathism. Among those studies that have examined variation between sexes with respect to subnasal prognathism, conflicting results have been reported with regard to whether males (Franklin et al., 2006) or females (Rosas and Bastir, 2002) tend to show increased prognathism. Although not directly addressing subnasal prognathism, Bigoni and colleagues (2010) did report on the dimorphic morphology of the surrounding nasal and palatal regions. While the MANOVA results in this study demonstrated a significant influence of sex on overall shape, subsequent ANOVA tests revealed that the individual PCs capturing prognathic shape changes are affected by population group but not sex or the interaction between sex and population (Table 4). Therefore, prognathism, when isolated from the remaining craniofacial morphology, does not appear to be a strongly sexually dimorphic characteristic among the populations studied.

This is consistent with earlier studies of craniofacial morphology and anatomy. McCollum and Ward (1997) found a significant effect of sex on subnasal form in two taxa of extant hominids but not among modern humans, and L'Abbé and colleagues (2011) found nonsignificant differences in alveolar prognathism based on sex. However, it has also been noted that levels of sexual dimorphism are accentuated with improved living conditions (Frayer and Wolpoff, 1985; Lazenby, 2001). Thus, the mixed sample of higher and lower socioeconomic groups used in this study may have had the effect of obscuring the potential for enhanced sexual dimorphism of subnasal prognathism among populations with better living conditions. 
PC scatterplots and post-hoc Tukey's analyses confirmed ancestral differences in prognathism. U.S. Black and Nubian individuals clustered together and showed higher levels of prognathism, while U.S. White, Portuguese, and Native American individuals showed lower levels of prognathism and were not significantly different from each other. This is consistent with qualitative descriptions of ancestral differences in prognathism (Bass, 1987; Gill and Rhine, 1990), as well as more recent nonmetric (Hurst, 2012; L’Abbé et al., 2011; Liebenberg et al., 2015) and geometric morphometric (Badawi-Fayad and Cabanis, 2007) assessments of subnasal prognathism among groups of different ancestries.

In this preliminary assessment, allometry, or the effect of size on shape, does not appear to have a significant effect on prognathism, as evidenced by the lack of correlation between centroid size and PC1, which reflected the most prognathic variation. Based on the landmarks chosen for this study, the shape components that capture prognathic shape changes, namely PC1 and PC3, were not significantly correlated with centroid size. In contrast, the shape variation captured by PC2 - the length of the facial skeleton changing in opposition to cranial vault height - did show a significant allometric influence. It must be noted that these correlations, or lack thereof, with centroid size may be due to including bregma in this study. As a result, cranial height was captured and had the potential to drastically affect centroid size between individuals with differing basion-bregma heights. However, Rosas and Bastir's study of allometry in the craniofacial complex (2002) also included bregma and found that the influence of size shifted modular proportions between the cranial vault and facial skeleton, resulting in the appearance of increased subnasal prognathism. This discrepancy between the results may be due to the use of primarily facial landmarks in this study and a broader range of landmarks, including the mandible, posterior vault, and cranial base, by Rosas and Bastir (2002). A second possibility, directing the cautious interpretation of these results, is the potential presence of non-linear relationships between size and some PC shape components.

Traditionally, the gnathic index has been used as a numeric shorthand in paleoanthropological, bioarchaeological, and forensic contexts to reflect the three-dimensional degree of prognathism of crania. This study presents new evidence indicating that this index only explains a small portion of the prognathic variation, as captured by more detailed morphometric analyses. Thus, the comparison of indices across studies as a method of assessing the relative degree of prognathism should be viewed with caution, unless accompanied by the corresponding 
comparison of the crania themselves. This morphometric analysis has also provided a preliminary step into the investigation of prognathism, indicating that prognathism may not be, as previously reported, a sexually dimorphic trait and may not be strongly influenced by allometry. Finally, the difficulties encountered in attempting to accurately evaluate prognathism and associated shape variation encourage the future study of more localized prognathic shape changes and the development of a revised definition for subnasal prognathism. A more accurate and standardized manner of reporting prognathism will facilitate more in-depth analyses and explanations of both the paleoanthropological evolution of the human cranium and modern craniofacial morphological variation.

\section{Acknowledgments}

The authors would like to thank the Smithsonian National Museum of Natural History, Cleveland Museum of Natural History, Bocage Museum (Lisbon), University of Tennessee, and University of Colorado (Boulder), and their respective curators, for access to the samples.

Finally, the authors wish to thank the editors and anonymous reviewers for their comments and suggestions, which helped strengthen this manuscript.

Grant sponsorship: The scan data used in this study were collected via funding provided by National Science Foundation (BCS-1061313). This sponsor had no role in study design; collection, analysis, or interpretation of data; in writing this manuscript; or in the decision to submit this article for publication. 


\section{References}

Aguilar, M.A., Aguilar, F.J., Negreiros, J., 2009. Off-the-shelf laser scanning and close-range digital photogrammetry for measuring agricultural soils microrelief. Biosystems Eng. 103, 504-517.

Badawi-Fayad, J., Cabanis, E., 2007. Three-dimensional Procrustes analysis of modern human craniofacial form. Anat. Rec. 290, 268-276.

Bass, W.M., 1987. Human Osteology: a Laboratory and Field Manual. Missouri Archaeological Society, Columbia.

Bastir, M. Rosas, A., 2004. Facial heights: Evolutionary relevance of postnatal ontogeny for facial orientation and skull morphology in humans and chimpanzees. J. Hum. Evol. 47, 359381.

Bigoni, L., Velemínská, J., Brůžek, J., 2010. Three-dimensional geometric morphometric analysis of cranio-facial sexual dimorphism in a central European sample of known sex. HOMO - J. Comp. Hum. Biol. 61, 16-32.

Björk, A., 1950. Some biological aspects of prognathism and occlusion of the teeth. Acta Odontol. 9, 1-40.

Brooks, S., Brooks, R.H., France, D., 1990. Alveolar prognathism contour, an aspect of racial identification. Skeletal Attribution of Race, Methods for Forensic Anthropology, pp. 41-46.

Brown, P., 2012. LB1 and LB6 Homo floresiensis are not modern human (Homo sapiens) cretins. J. Hum. Evol. 62, 201-224.

Brown, P., Maeda, T., 2004. Post-Pleistocene diachronic change in East Asian facial skeletons: The size, shape and volume of the orbits. Anthropol. Sci, 112, 29-40.

Bruner, E., Manzi, G., 2004. Variability in facial size and shape among North and East African human populations. Ital. J. Zool. 71, 51-56.

Bruzek, J., 2002. A method for visual determination of sex, using the human hip bone. Am. J. Phys. Anthropol. 117, 157-168.

Buikstra, J.E., Ubelaker, D.H., 1994. Standards for Data Collection from Human Skeletal Remains. Fayetteville Arkansas Archaeological Survey, Fayetteville.

Chang, H., Liu, P., Yang, Y., Lin, H., Chang, C., 2006. Craniofacial morphometric analysis of mandibular prognathism. J. Oral Rehabil. 33, 183-193. 
Douglas, M.T., Pietrusewsky, M., Ikehara-Quebral, R.M., 1997. Skeletal biology of Apurguan: A precontact Chamorro site on Guam. Am. J. Phys. Anthropol. 104, 291-313.

Fourie, Z., Damstra, J., Gerrits, P.O., Ren, Y., 2011. Evaluation of anthropometric accuracy and reliability using different three-dimensional scanning systems. Forensic Sci. Int. 207, 127134.

Franklin, D., Freedman, L., Milne, N., Oxnard, C., 2006. A geometric morphometric study of sexual dimorphism in the crania of indigenous Southern Africans. S. Afr. J. Sci. 102, 229-238.

Franks, E.M., Cabo, L.L., 2014. Quantifying asymmetry: Ratios and alternatives. Am. J. Phys. Anthropol. 154, 498-511.

Frayer, D.W., Wolpoff, M.H., 1985. Sexual dimorphism. Annu. Rev. Anthropol. 14, 429-473.

Garvin, H.M., Ruff, C.B., 2012. Sexual dimorphism in skeletal browridge and chin morphologies determined using a new quantitative method. Am. J. Phys. Anthropol. 147, 661-670.

Gill, G.W., Rhine, S. (Eds.), 1990. Skeletal Attribution of Race: Methods for Forensic Anthropology. Anthropological papers no. 4. Maxwell Museum of Anthropology, Albuquerque.

Gonzalez-Jose, R., Martinez-Abadias, N., Gonzalez-Martin, A., Bautista-Martinez, J., GomezValdes, J., Quinto, M., Hernandez, M., 2007. Detection of a population replacement at the Classic-Postclassic transition in Mexico. Proc. Biol. Sci. 274, 681-688.

Green, R., Chapman, P.M., 2011. The problem with indices. Mar. Pollut. Bull. 62, 1377-1380.

Hanihara, T., 2000. Frontal and facial flatness of major human populations. Am. J. Phys. Anthropol. 111, 105-134.

Hennessy, R.J., Stringer, C.B., 2002. Geometric morphometric study of the regional variation of modern human craniofacial form. Am. J. Phys. Anthropol. 117, 37-48.

Hershkovitz, I., Galili, E., 1991. The morphological significance of the Homo I skeleton from the PPNB submerged site at Atlit-Yam, Israel. Bulletins Et Mémoires De La Société D'Anthropologie De Paris 3, 83-96.

Hershkovitz, I., Speirs, M., Frayer, D., Nadel, D., Wish-Baratz, S., Arensburg, B., 1995. Ohalo II H2: A 19,000-year-old skeleton from a water-logged site at the Sea of Galilee, Israel. Am. J. Phys. Anthropol. 96, 215-234. 
Howells, W.W., 1973. Cranial Variation in Man. A study by multivariate analysis of patterns of difference among recent human populations. Papers of the Peabody Museum of Archaeology and Ethnology 67, 1-259.

Hurst, C.V., 2012. Morphoscopic trait expressions used to identify Southwest Hispanics. J. Forensic Sci. 57, 859-865.

Huxley, T.H., 1863. Evidence as to Man's Place in Nature. D. Appleton and Company, New York.

Kennedy, K.A., Possehl, G.L., 2012. Were there commercial communications between prehistoric Harappans and African populations? Adv. Anthropol. 2, 169-180.

Klingenberg, C.P., 2011. MorphoJ: an integrated software package for geometric morphometrics. Mol. Ecol. Resour. 11, 353-357.

Klingenberg, C.P., 2013. Visualizations in geometric morphometrics: how to read and how to make graphs showing shape changes. Hystrix 24, 15-24.

L’Abbé, E.N., Van Rooyen, C., Nawrocki, S.P., Becker, P.J., 2011. An evaluation of non-metric cranial traits used to estimate ancestry in a South African sample. Forensic Sci. Int. 209, 195.e1-195.e7.

Lazenby, R.A., 2001. Sex dimorphism and bilateral asymmetry: modeling developmental instability and functional adaptation. Am. J. Phys. Anthropol. Suppl. 32, 96.

Liebenberg, L., Stull, K.E., L’Abbé, E.N., Botha, D., 2015. Evaluating the accuracy of cranial indices in ancestry estimation among South African groups. J. Forensic Sci. 60, 1277-1282.

Lieberman, D.E., Ross, C.F., Ravosa, M.J., 2000. The primate cranial base: Ontogeny, function, and integration. Am. J. Phys. Anthropol. 113, 117-169.

Lieberman, D., 2011. The evolution of the human head. Harvard University Press, Cambridge.

Lynch, J.M., Wood, C.G., Luboga, S., 1996. Geometric morphometrics in primatology: Craniofacial variation in Homo sapiens and Pan troglodytes. Folia Primatol. 67, 15-39.

Martin, R., 1957. Lehrbuch der Anthropologie in systematischer Darstellung mit besonderer Berucksichtigung der anthropologischen Methoden. Zweiter Band: Kraniologie, Osteologie, $3^{\text {rd }}$ ed. Gustav Fischer, Stuttgart.

Martin, R., Knussmann, R., 1988. Lehrbuch der Anthropologie und Humangenetik. Gustav Fischer, Nueva York, Stuttgart. 
Martínez-Abadías, N., González-José, R., González-Martín, A., van der Molen, S., Talavera, A., Hernández, P., Hernández, M., 2006. Phenotypic evolution of human craniofacial morphology after admixture: A geometric morphometrics approach. Am. J. Phys. Anthropol. 129, $387-$ 398.

McCollum, M.A., Ward, S.C., 1997. Subnasoalveolar anatomy and hominoid phylogeny: Evidence from comparative ontogeny. Am. J. Phys. Anthropol. 102, 377-405.

Neaux, D., Guy, F., Gilissen, E., Coudyzer, W., Ducrocq, S., 2013. Covariation between midline cranial base, lateral basicranium, and face in modern humans and chimpanzees: A 3D geometric morphometric analysis. Anat. Rec. 296, 568-579.

O'Higgins, P., Jones, N., 2006. Tools for statistical shape analysis. Hull York Medical School. http://sites.google.com/site/hymsfme/resources.

Orish, C.N., Ibeachu, P.C., 2016. Craniometric indices of Nigeria skulls. Int. J. Anat. Appl. Physiol. 2, 6-13.

Ousley, S., Jantz, R., Freid, D., 2009. Understanding race and human variation: Why forensic anthropologists are good at identifying race. Am. J. Phys. Anthropol. 139, 68-76.

Owsley, D.W., Bass, W.M., 1979. A demographic analysis of skeletons from the Larson site (39WW2) Walworth County, South Dakota: vital statistics. Am. J. Phys. Anthropol. 51, 145154.

Owsley, D.W., Jantz, R.L., 1994. Skeletal Biology in the Great Plains: Migration, Warfare, Health, and Subsistence. Smithsonian Institution Press, Washington DC.

Patriquin, M.L., 2013. The Relationship between Masticatory Stress and Prognathism: A finite Element and Morphometric Study. PhD dissertation, University of Pretoria, South Africa. Phenice, T.W., 1969. A newly developed visual method of sexing the os pubis. Am. J. Phys. Anthropol. 30, 297-301.

Pietrusewsky, M., Douglas, M.T., 1992. The skeletal biology of an historic Hawaiian cemetery: Familial relationships. HOMO - J. Comp. Hum. Biol. 43, 245-262

Quatrehomme, G., Balaguer, T., Staccini, P., Alunni-Perret, V., 2007. Assessment of the accuracy of three-dimensional manual craniofacial reconstruction: A series of 25 controlled cases. Int. J. Legal Med. 121, 469-475.

Richard, A.H., Parks, C.L., Monson, K.L., 2014. Accuracy of standard craniometrics measurements using multiple data formats. Forensic Sci. Int. 242, 177-185. 
Richtsmeier, J.T., Cheverud, J.M., Lele, S., 1992. Advances in anthropological morphometrics. Annu. Rev. Anthropol. 21, 283-305.

Rosas, A., Bastir, M., 2002. Thin-plate spline analysis of allometry and sexual dimorphism in the human craniofacial complex. Am. J. Phys. Anthropol. 117, 236-245.

Sholts, S.B., Wärmländer, S.K.T.S., Flores, L.M., Miller, K.W.P., Walker, P.L., 2010. Variation in the measurement of cranial volume and surface area using $3 \mathrm{D}$ laser scanning technology. J. Forensic Sci. 55, 871-876.

Sholts, S.B., Flores, L.M., Walker, P.L., Wärmländer, S.K.T.S., 2011. Comparison of coordinate measurement precision of different landmark types on human crania using 3D laser scanner and a 3D digitizer: implications for applications of digital morphometrics. Int. J. Osteoarchaeol. 21, 535-543.

Sibley, L.M., Armelagos, G.J., Van Gerven, D.P., 1992. Obstetric dimensions of the true pelvis in a Medieval population from Sudanese Nubia. Am. J. Phys. Anthropol. 89, 421-430.

Slice, D.E., 2005. Modern morphometrics. In: Slice, D.E. (Ed.), Modern Morphometrics in Physical Anthropology. Kluwer Acad./Plenum, New York, pp. 1-45.

Spoor, F., Leakey, M.G., Leakey, L.N., 2005. Correlation of cranial and mandibular prognathism in extant and fossil hominids. Trans. R. Soc. S. Afr. 60, 85-89.

Spradley, M.K., Jantz, R.L., 2011. Sex estimation in forensic anthropology: skull versus postcranial elements. J. Forensic Sci. 56, 289-296.

Thorne, A.G., Wolpoff, M.H., 1981. Regional continuity in Australasian Pleistocene hominid evolution. Am. J. Phys. Anthropol. 55, 337-349.

Turner, B.L., Edwards, J.L., Quinn, E.A., Kingston, J.D., Van Gerven, D.P., 2007. Age-related variation in isotopic indicators of diet at medieval Kulubnarti, Sudanese Nubia. Int. J. Osteoarchaeol. 17, 1-25.

van Rensburg, J., Gerhardus, J., Wilke, D.N., Kok, S., 2012. Human skull shape and masticatory induced stress: Objective comparison through the use of non-rigid registration. Int. J. Numer. Meth. Biomed. Eng. 28, 170-185.

von Cramon-Taubadel, N., Frazier, B.C., Lahr, M.M., 2007. The problem of assessing landmark error in geometric morphometrics: theory, methods, and modifications. Am. J. Phys. Anthropol. 134, 24-35. 
Walker, P.L., 2008. Sexing skulls using discriminant function analysis of visually assessed traits. Am. J. Phys. Anthropol. 136, 39-50.

Walrath, D.E., Turner, P., Bruzek, J., 2004. Reliability test of the visual assessment of cranial traits for sex determination. Am. J. Phys. Anthropol. 125, 132-137.

Weisensee, K.E., Jantz, R.L., 2011. Secular changes in craniofacial morphology of the Portuguese using geometric morphometrics. Am. J. Phys. Anthropol. 145, 548-559.

Williams, B.A., Rogers, T.L., 2006. Evaluating the accuracy and precision of cranial morphological traits for sex determination. J. Forensic Sci. 51, 729-735.

Wu, X., Liu, W., Zhang, Q., Zhu, H., Norton, C.J., 2007. Craniofacial morphological microevolution of Holocene populations in northern China. Chinese Sci. Bull. 52, 1661-1668.

Zelditch, M.L., Swiderski, D.L., Sheets, H.D., Fink, W.L., 2004. Geometric Morphometrics for Biologists. Elsevier Press, London. 


\section{Legends for Figures}

Fig. 1. Right lateral view of a modern human skull illustrating the geometric relationship between the measurements in the gnathic index. A color version of the figure is available online.

Fig. 2. (A) Anterior and inferior views illustrating landmarks collected; (B) right lateral view of a wireframe produced by Morphologika, illustrating the positions of the craniofacial landmarks in this view. A color version of the figure is available online.

Fig. 3. Right lateral views of wireframes exported from Morphologika following GPA and PCA analyses, depicting the extreme positive (right column) and negative (left column) values of PCs $1-6$.

Fig. 4. Right lateral views of wireframes from Figure 3, re-oriented along the axis defined by nasion-alare to demonstrate any anterior projection of the subnasal maxillary region relative to the upper face. Extreme positive wireframes are in black, and extreme negative wireframes are in gray. A color version of the figure is available online.

Fig. 5. Comparison of crania aligned in Frankfurt horizontal that exhibit visually different levels of subnasal maxillary prognathism, despite having the same gnathic index. (A) GI = 88.9; (B) GI $=94.9 ;(\mathrm{C}) \mathrm{GI}=103$. A color version of the figure is available online.

Fig. 6. Scatter plot of the first and third principal components. Legend: $F=$ females; $M=$ males; $\mathrm{B}=$ U.S. Black; $\mathrm{K}=$ Kulubnarti medieval Nubian; $\mathrm{N}=$ Native American; $\mathrm{P}=$ Portuguese; $\mathrm{W}=$ U.S. White. Original specimens from the extremes of the axes are presented for visualization. A color version of the figure is available online.

Fig. 7. Scatter plot of the second and sixth principal components. Legend: $F=$ females; $M=$ males; $\mathrm{B}=$ U.S. Black; $\mathrm{K}=$ Kulubnarti medieval Nubian; $\mathrm{N}=$ Native American; $\mathrm{P}=$ Portuguese; 
$\mathrm{W}=$ U.S. White. Original specimens from the extremes of the axes are presented for visualization. A color version of the figure is available online.

Fig. 8. Geometric limitations of the gnathic index (GI). GI represents the cosine of the angle between the lines basion-prosthion (B-P) and basion-nasion (B-N), if the three landmarks formed a right triangle (8A). If the angle $\theta$ were constant, a larger projection of prosthion with respect to basion would result in a higher GI (8B). However, the GI cannot distinguish between changes in relative lengths and changes in angle aperture (8C and 8D). In (8C) B-N is rotated, without changing length, such that nasion is placed higher and more posteriorly than in (8A), resulting in higher prognathism (represented by the shaded area). Still, (8C) shares the same GI with (8A). In (8D), B-P has rotated downwards around basion, again with no change in length, resulting in a smaller prognathism. Thus, $(8 \mathrm{~A}),(8 \mathrm{C})$ and $(8 \mathrm{D})$ all share the same GI (the three figures share the same B-P and B-N lengths) but show differing levels of prognathism. Similar problems would occur with isometric rotations around nasion or prosthion (not illustrated). 
Table 1. Definitions of cranial landmarks collected.

\begin{tabular}{|c|c|c|c|}
\hline Number & Landmark & $\begin{array}{c}\text { Midline or } \\
\text { right/left }\end{array}$ & Definition \\
\hline 1 & Bregma & $\mathrm{M}$ & $\begin{array}{l}\text { The ectocranial midline point where the } \\
\text { coronal suture and sagittal sutures } \\
\text { intersect. }\end{array}$ \\
\hline 2 & Nasion & M & $\begin{array}{l}\text { The point of intersection between the } \\
\text { frontonasal suture and the midsagittal } \\
\text { plane. }\end{array}$ \\
\hline 3,11 & Dacryon & $\mathrm{R} / \mathrm{L}$ & $\begin{array}{l}\text { The point on the medial border of the } \\
\text { orbit at which the frontal, lacrimal and } \\
\text { maxilla intersect. }\end{array}$ \\
\hline 4,12 & Frontomalare temporale & $\mathrm{R} / \mathrm{L}$ & $\begin{array}{l}\text { The most laterally positioned point on } \\
\text { the fronto-zygomatic suture. }\end{array}$ \\
\hline 5,13 & Infraorbital foramen & $\mathrm{R} / \mathrm{L}$ & $\begin{array}{l}\text { The most inferior point of the } \\
\text { infraorbital foramen. }\end{array}$ \\
\hline 6,14 & Alare & $\mathrm{R} / \mathrm{L}$ & $\begin{array}{l}\text { The most lateral points on the nasal } \\
\text { aperture. }\end{array}$ \\
\hline 7,15 & Inferior nasal border & $\mathrm{R} / \mathrm{L}$ & Most inferior point of the nasal aperture. \\
\hline 8 & Prosthion & M & $\begin{array}{l}\text { The most inferior point in the midline } \\
\text { on the alveolar process of the maxillae. }\end{array}$ \\
\hline 9,16 & Posterior canine & $\mathrm{R} / \mathrm{L}$ & $\begin{array}{l}\text { The most inferior point on the alveolar } \\
\text { process of the maxilla along the } \\
\text { posterior border of the maxillary canine. }\end{array}$ \\
\hline 10,17 & Posterior $\mathrm{M}^{2}$ & $\mathrm{R} / \mathrm{L}$ & $\begin{array}{l}\text { The most inferior point on the alveolar } \\
\text { process of the maxilla along the } \\
\text { posterior border of the maxillary second } \\
\text { molar. }\end{array}$ \\
\hline 18 & Staurion & M & $\begin{array}{l}\text { Intersection of the medial palatine and } \\
\text { transverse palatine sutures. }\end{array}$ \\
\hline 19 & Basion & $\mathrm{M}$ & $\begin{array}{l}\text { The midline point on the anterior } \\
\text { margin of the foramen magnum. }\end{array}$ \\
\hline
\end{tabular}


Table 2. Sample demographics.

\begin{tabular}{lrrr} 
Ancestry & Female & Male & Total \\
\hline U.S. White & 11 & 27 & 38 \\
U.S. Black & 29 & 40 & 69 \\
Nubian & 12 & 12 & 24 \\
Native American & 7 & 14 & 21 \\
Portuguese & 19 & 21 & 40 \\
\hline Total & $\mathbf{7 8}$ & $\mathbf{1 1 4}$ & $\mathbf{1 9 2}$ \\
\hline
\end{tabular}


Table 3. Sample averages and standard deviations for gnathic index measurements.

\begin{tabular}{|c|c|c|c|c|c|c|}
\hline \multirow[t]{2}{*}{ Population } & \multicolumn{2}{|c|}{$\begin{array}{c}\text { Basion-Prosthion } \\
\text { Length }(\mathbf{m m})\end{array}$} & \multicolumn{2}{|c|}{$\begin{array}{l}\text { Basion-Nasion } \\
\text { Length }(\mathbf{m m})\end{array}$} & \multicolumn{2}{|c|}{$\begin{array}{l}\text { Gnathic } \\
\text { Index }\end{array}$} \\
\hline & Mean & S.D. & Mean & S.D. & Mean & S.D. \\
\hline U.S. White & 93.6 & 7.0 & 101.3 & 5.4 & 92.4 & 4.3 \\
\hline U.S. Black & 99.1 & 6.2 & 97.3 & 5.4 & 102.0 & 3.5 \\
\hline Nubian & 95.1 & 5.1 & 96.4 & 4.3 & 98.7 & 4.4 \\
\hline Native American & 96.1 & 3.0 & 100.9 & 3.5 & 95.3 & 2.6 \\
\hline Portuguese & 91.4 & 5.4 & 96.7 & 5.3 & 94.6 & 3.7 \\
\hline
\end{tabular}


Table 4. Summary of the amount of shape variance explained by each PC and the correlation between PC scores, prognathic shape change, and the gnathic index.

\begin{tabular}{lccc} 
Variance & $\begin{array}{c}\text { Prognathic } \\
\text { Explained }\end{array}$ & $\begin{array}{c}\text { Correlation (r) to } \\
\text { Gnathic Index }\end{array}$ \\
\hline PC1 & $17.2 \%$ & Yes & $0.604^{* *}$ \\
PC2 & $13.1 \%$ & No & $-0.448^{* *}$ \\
PC3 & $7.2 \%$ & Yes & $0.389^{* *}$ \\
PC4 & $7.0 \%$ & No & -0.080 \\
PC5 & $6.0 \%$ & No & 0.039 \\
PC6 & $5.1 \%$ & No & $-0.301^{* *}$ \\
\hline
\end{tabular}

$* p<0.05$

$* * p<0.01$

\pm Interpreted by the author (KML) as a change in the anterior projection of the maxilla (prosthion) relative to the upper face. This was determined visually using the graphic outputs from Morphologika, MorphoJ and by referencing original specimens. 
Table 5. P-values of MANOVA and ANOVA tests regarding the effect of sex and population group on shape variation.

\begin{tabular}{llll} 
Shape Variation & Sex & Population & Sex $\times$ Population \\
\hline PC1 & 0.114 & $0.000^{* *}$ & 0.782 \\
PC2 & 0.124 & $0.000^{* *}$ & 0.328 \\
PC3 & 0.455 & $0.000^{* *}$ & 0.755 \\
PC4 & 0.345 & $0.007^{* *}$ & 0.172 \\
PC5 & $0.021^{*}$ & 0.062 & 0.375 \\
PC6 & 0.138 & $0.000^{* *}$ & 0.957 \\
All 50 PCs & $0.000^{* *}$ & $0.000^{* *}$ & 0.369 \\
(MANOVA) & & & \\
\hline
\end{tabular}

$* p<0.05$

$* * p<0.01$ 
Table 6. Homogenous population subsets (represented by letters) resulting from Tukey's post hoc analyses.

\begin{tabular}{lcccccc} 
Population & PC1 & PC2 & PC3 & PC4 & PC5 & PC6 \\
\hline U.S. White & A & A & A & A & A & A \\
Portuguese & A & A & B & A & A & B \\
Nubian & B & A & C & A & A & A \\
U.S. Black & B & B & B & B & A & A,B \\
Native American & A & B & A,B & B & A & A,B \\
\hline
\end{tabular}


Table 7. $\mathrm{r}^{2}$ values for centroid size on PCA scores for the first six principal components.

\begin{tabular}{|c|c|c|c|c|c|c|}
\hline Centroid Size & PC1 & PC2 & PC3 & PC4 & PC5 & PC6 \\
\hline \multicolumn{7}{|l|}{ U.S. Black } \\
\hline Female & 0.000 & $0.218^{*}$ & 0.034 & 0.088 & 0.038 & $0.140^{*}$ \\
\hline Male & 0.051 & $0.205 * *$ & 0.005 & 0.029 & 0.000 & 0.006 \\
\hline Total & 0.038 & $0.191 * *$ & 0.000 & $0.057^{*}$ & $0.067^{*}$ & 0.013 \\
\hline \multicolumn{7}{|l|}{ Nubian } \\
\hline Female & 0.070 & $0.457^{*}$ & 0.054 & 0.003 & 0.016 & 0.077 \\
\hline Male & 0.316 & $0.609 * *$ & 0.152 & 0.004 & 0.136 & 0.009 \\
\hline Total & 0.005 & $0.378 * *$ & 0.029 & 0.002 & 0.021 & 0.000 \\
\hline \multicolumn{7}{|c|}{ Native American } \\
\hline Female & 0.002 & 0.386 & 0.320 & 0.066 & 0.551 & 0.474 \\
\hline Male & 0.181 & 0.092 & 0.054 & 0.257 & 0.054 & 0.064 \\
\hline Total & 0.115 & 0.126 & 0.134 & 0.032 & $0.310 * *$ & 0.001 \\
\hline \multicolumn{7}{|l|}{ Portuguese } \\
\hline Female & 0.087 & $0.320^{*}$ & 0.156 & 0.124 & 0.031 & 0.022 \\
\hline Male & 0.009 & $0.350 * *$ & 0.022 & 0.135 & 0.060 & 0.081 \\
\hline Total & 0.085 & $0.159 *$ & 0.001 & 0.000 & 0.084 & 0.066 \\
\hline \multicolumn{7}{|l|}{ U.S. White } \\
\hline Female & 0.064 & 0.032 & $0.483^{*}$ & 0.010 & 0.000 & 0.089 \\
\hline Male & 0.001 & 0.132 & $0.179 *$ & 0.051 & 0.004 & 0.010 \\
\hline Total & 0.000 & $0.186 * *$ & 0.019 & $0.126^{*}$ & 0.006 & 0.026 \\
\hline \multicolumn{7}{|l|}{ Pooled sample } \\
\hline Female & 0.000 & $0.275 * *$ & $0.057^{*}$ & 0.014 & 0.002 & 0.045 \\
\hline Male & 0.000 & $0.284 * *$ & 0.016 & 0.016 & 0.014 & 0.002 \\
\hline Total & 0.007 & $0.219 * *$ & 0.017 & 0.006 & $0.045 * *$ & 0.012 \\
\hline
\end{tabular}

\footnotetext{
$* p<0.05$
}

$* * p<0.01$ 


\section{Figure 1.}

* Intended to be reproduced in color on the Web (free of charge) and in black-and-white in print
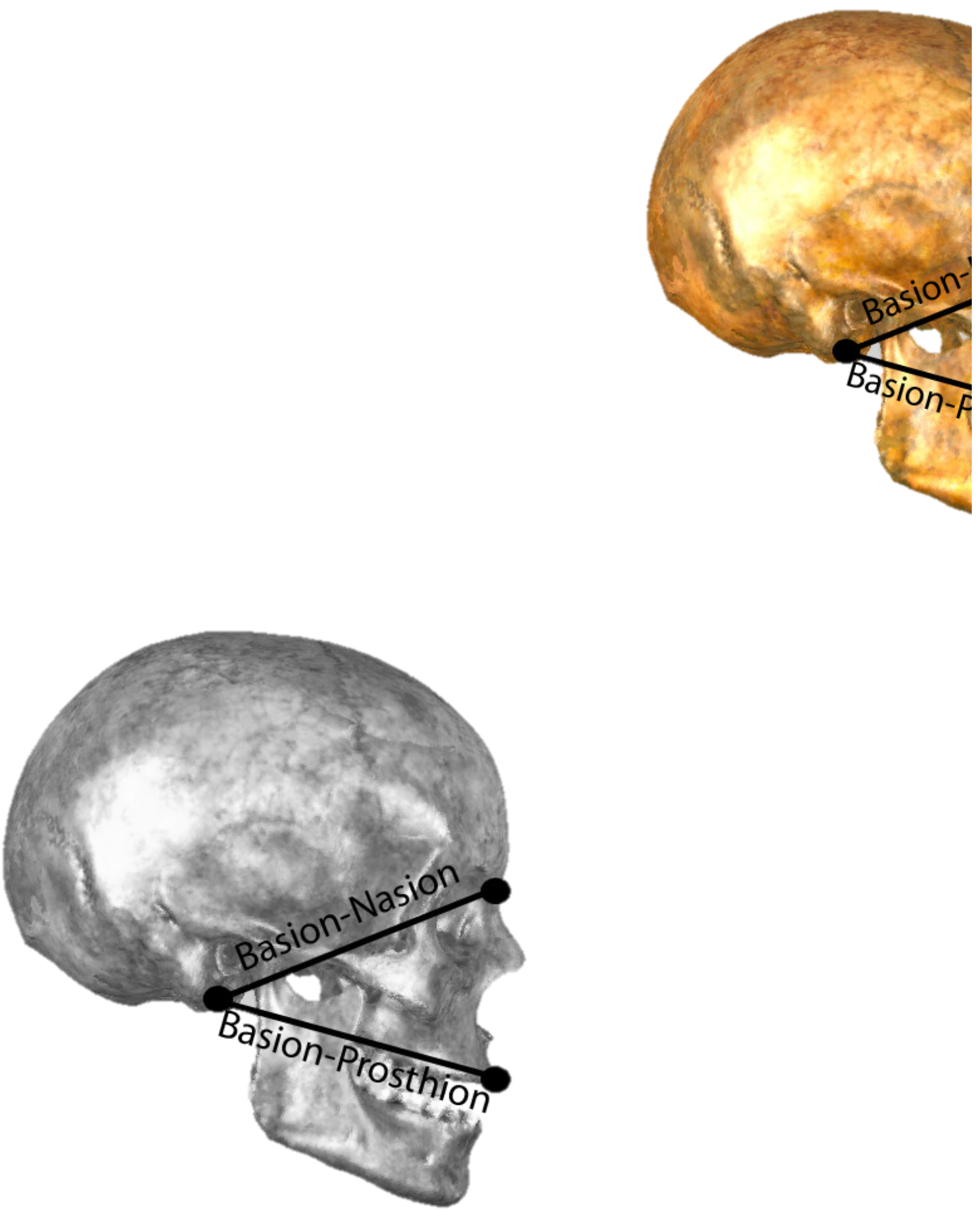
Figure 2.

* Intended to be reproduced in color on the Web (free of charge) and in black-and-white in print
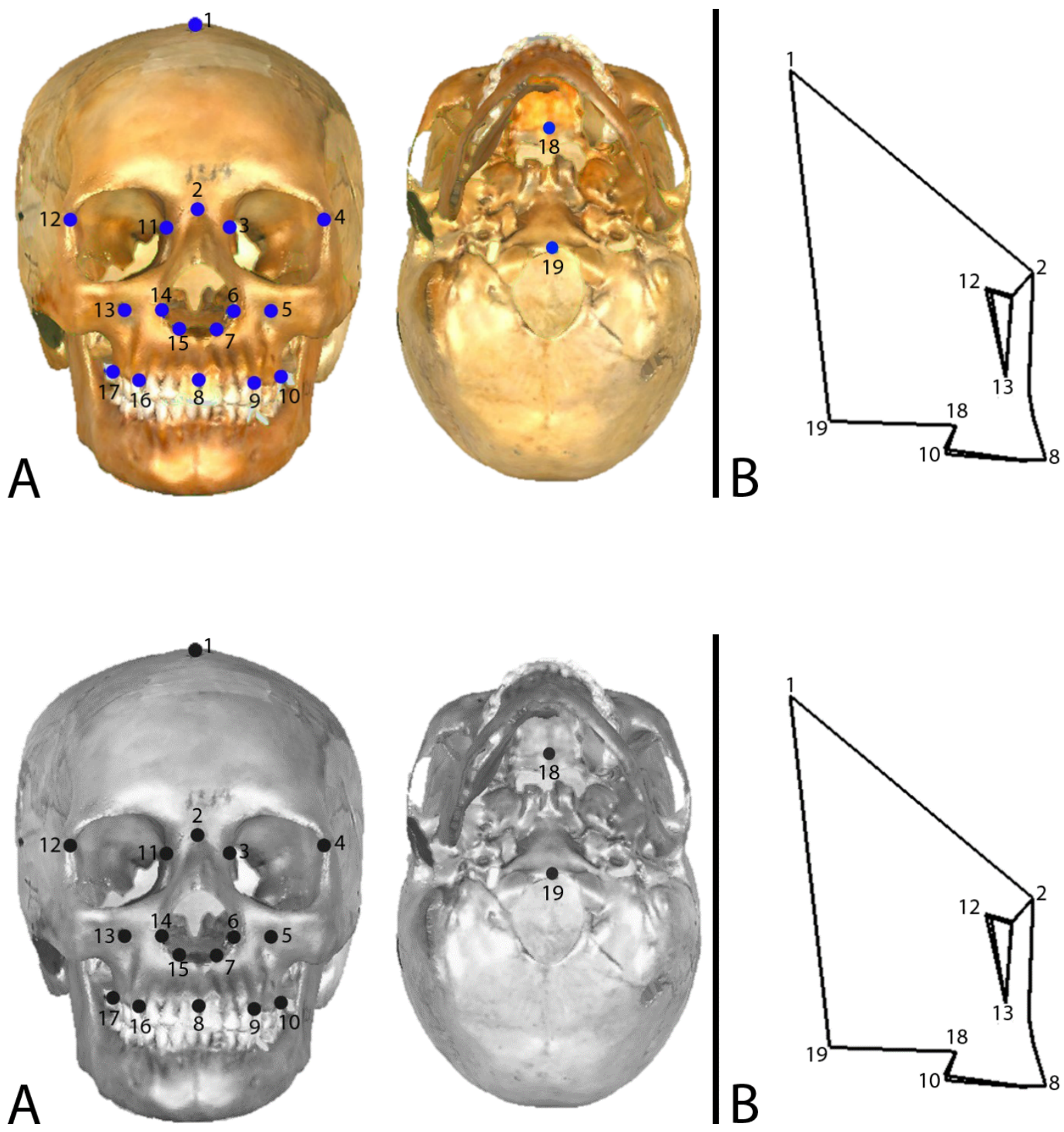
Figure 3. 

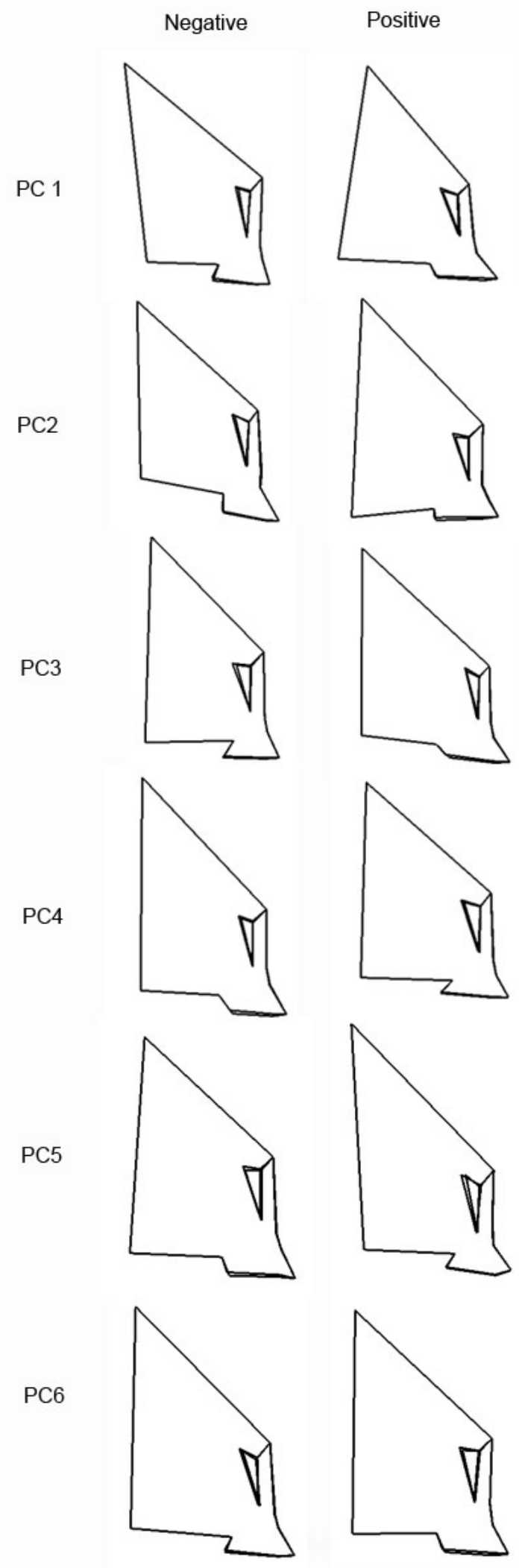

Figure 4. 
* Intended to be reproduced in color on the Web (free of charge) and in black-and-white in print
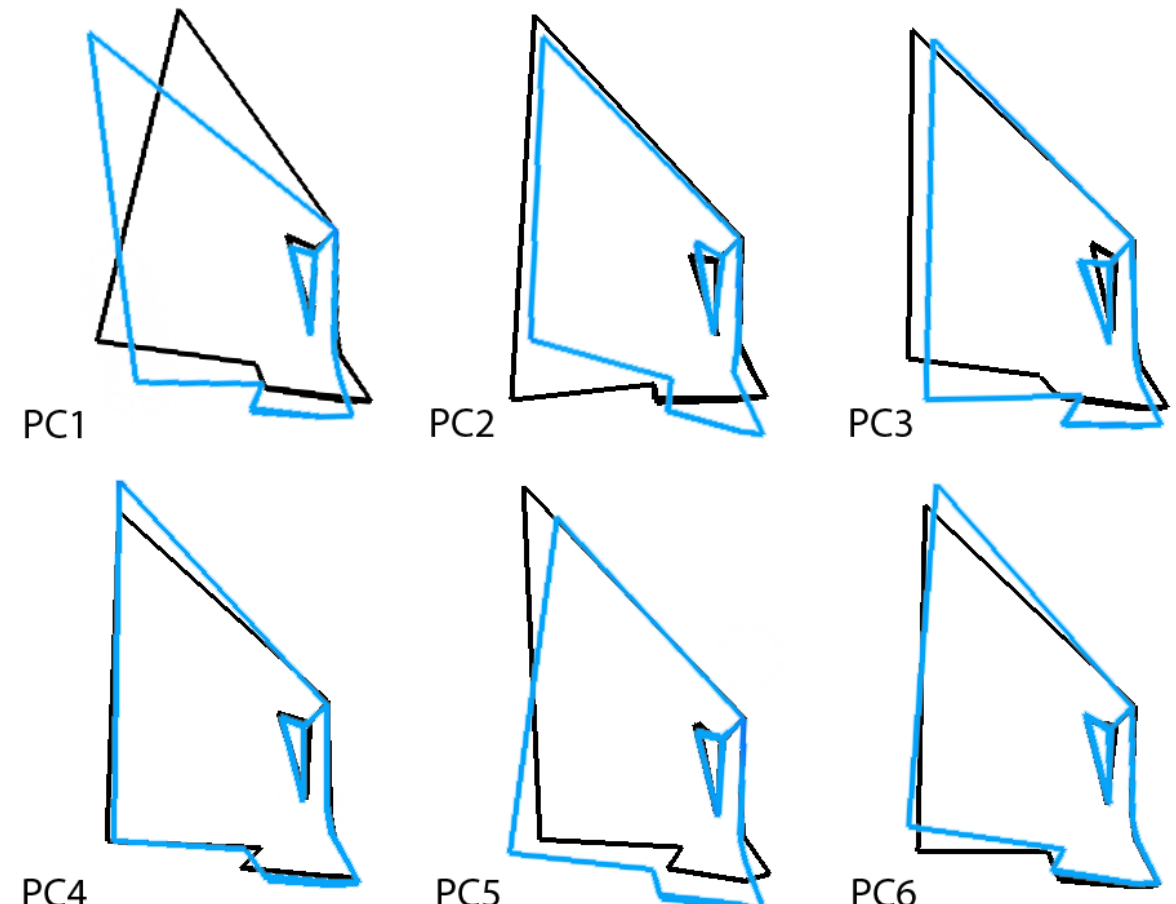

PC4
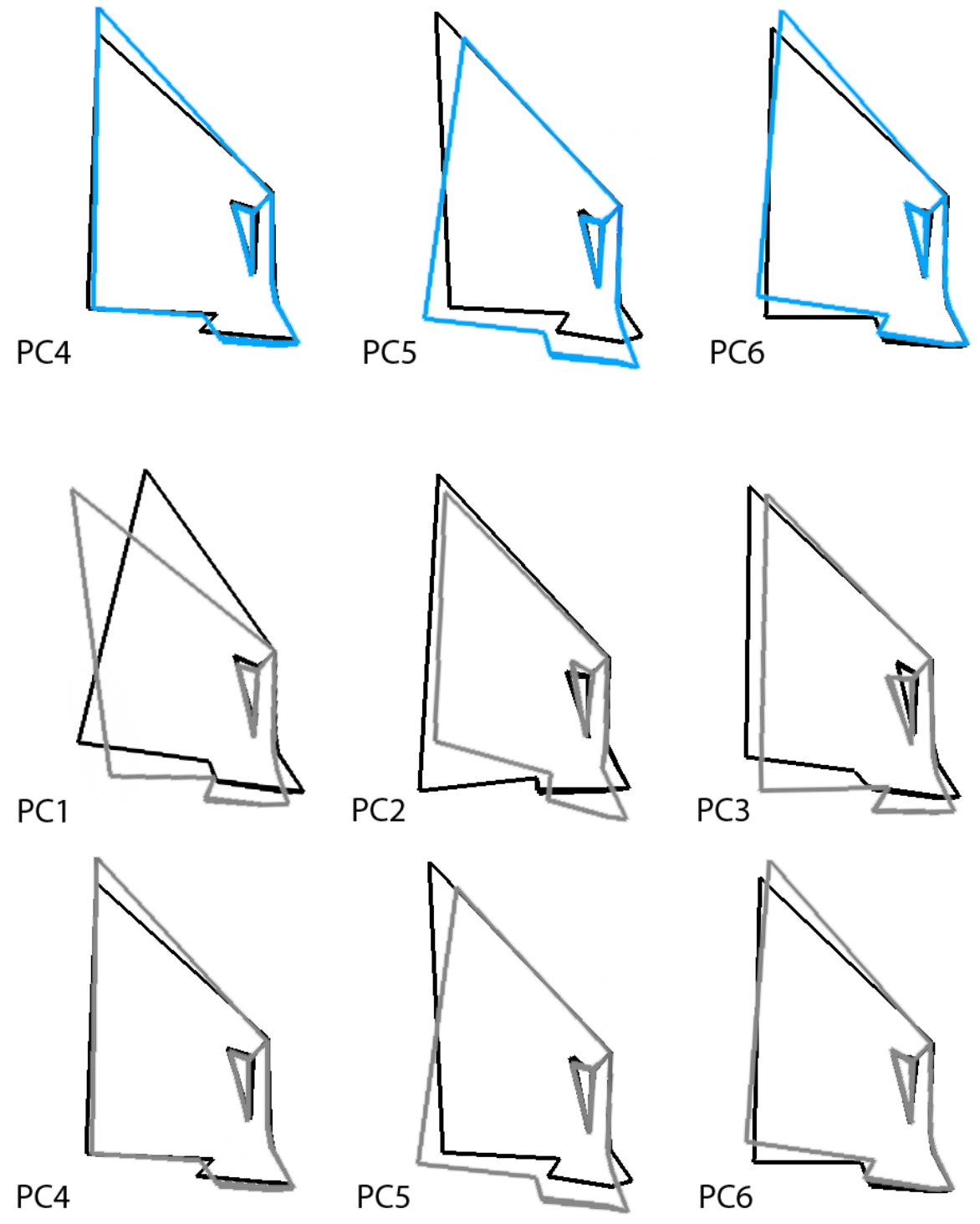
Figure 5.

* Intended to be reproduced in color on the Web (free of charge) and in black-and-white in print
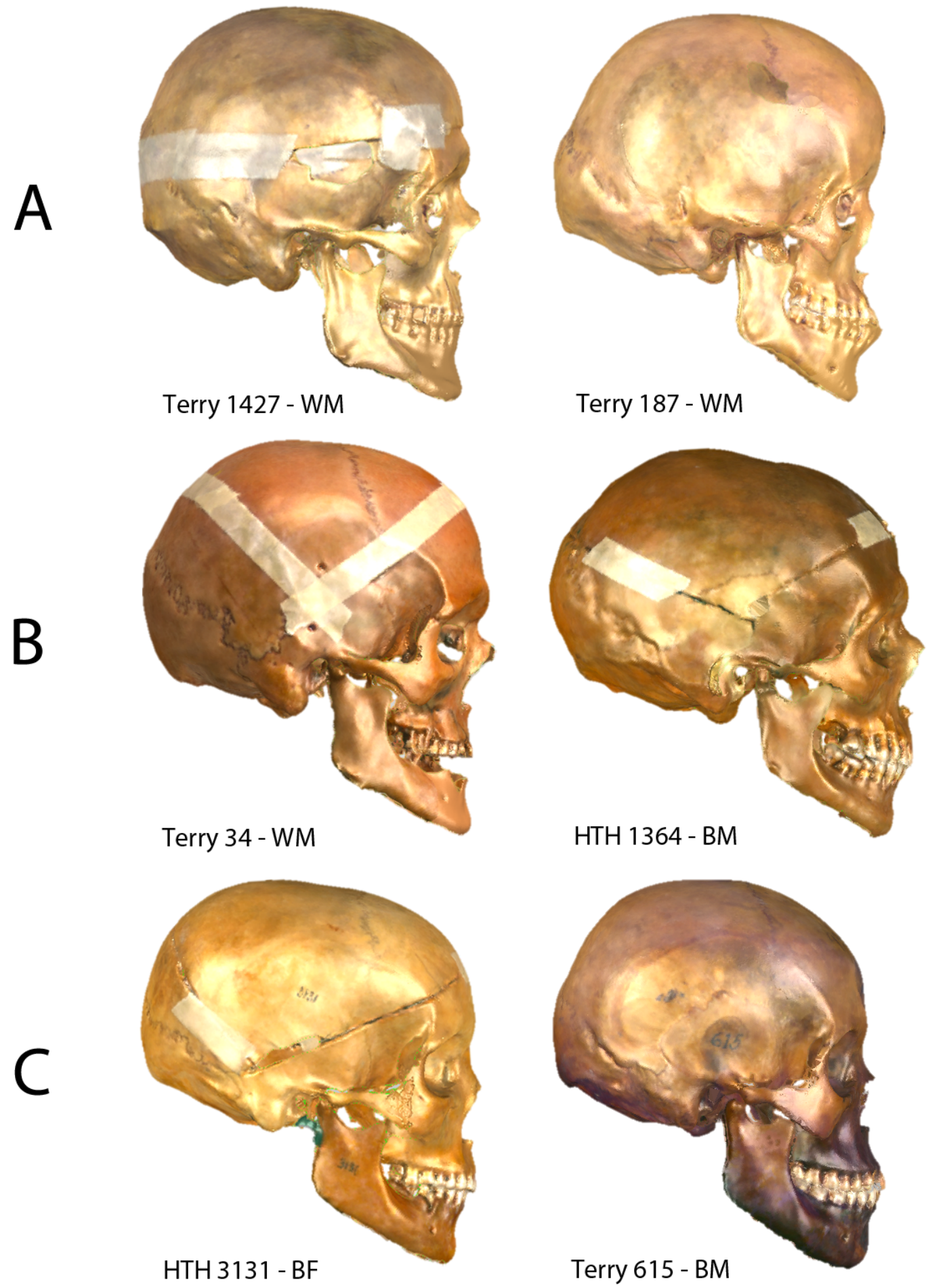

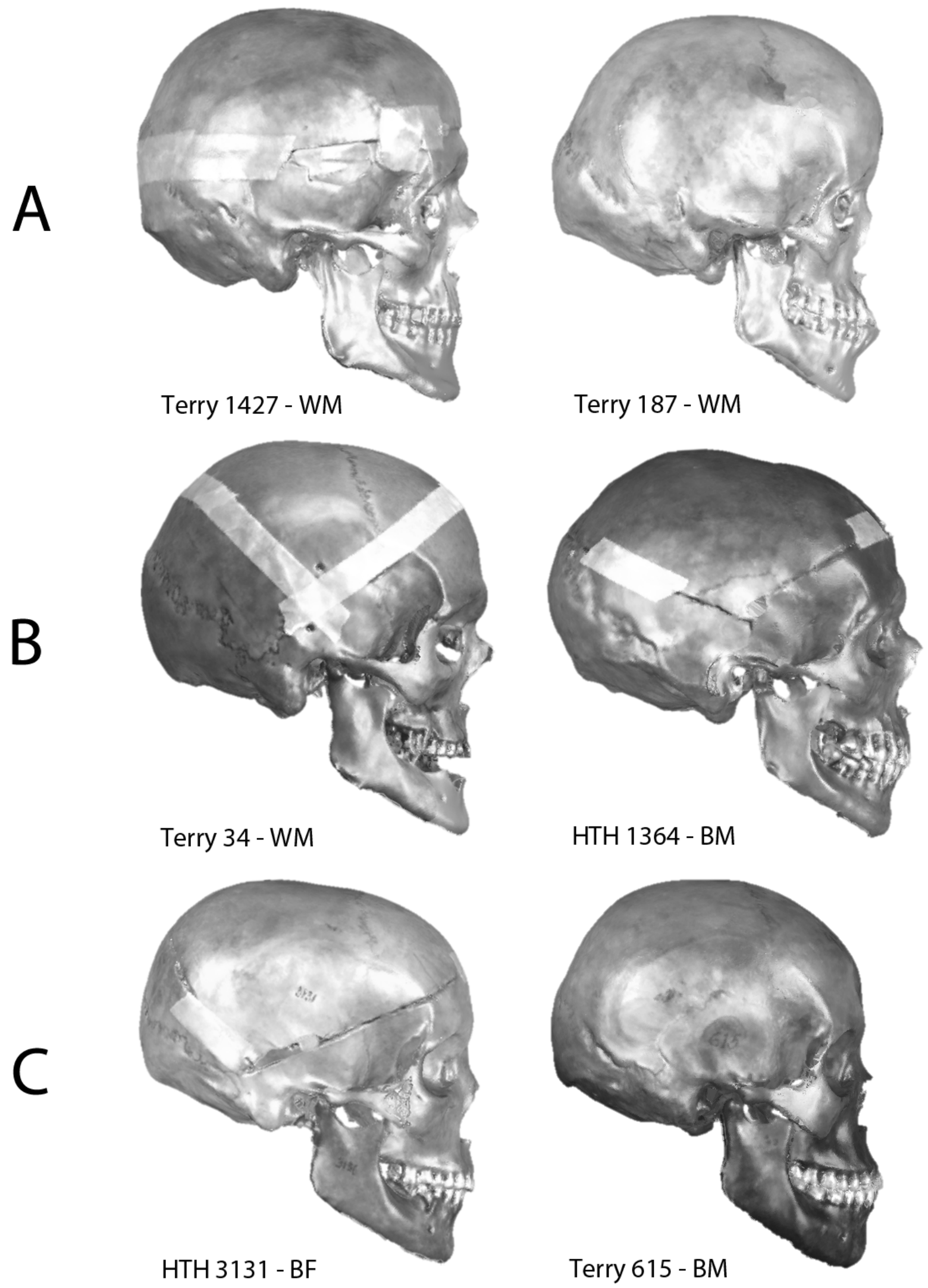


\section{Figure 6.}

* Intended to be reproduced in color on the Web (free of charge) and in black-and-white in print

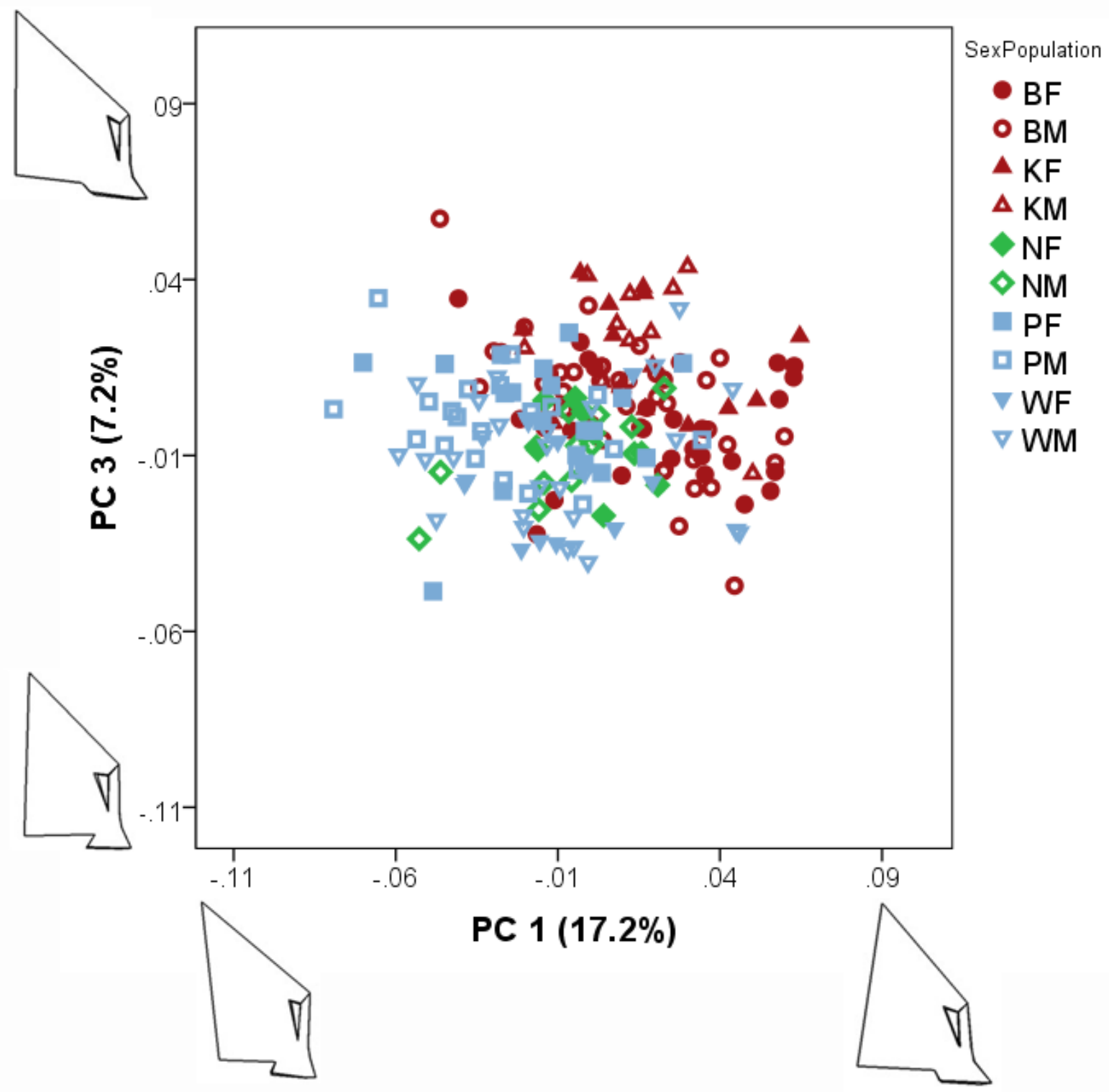




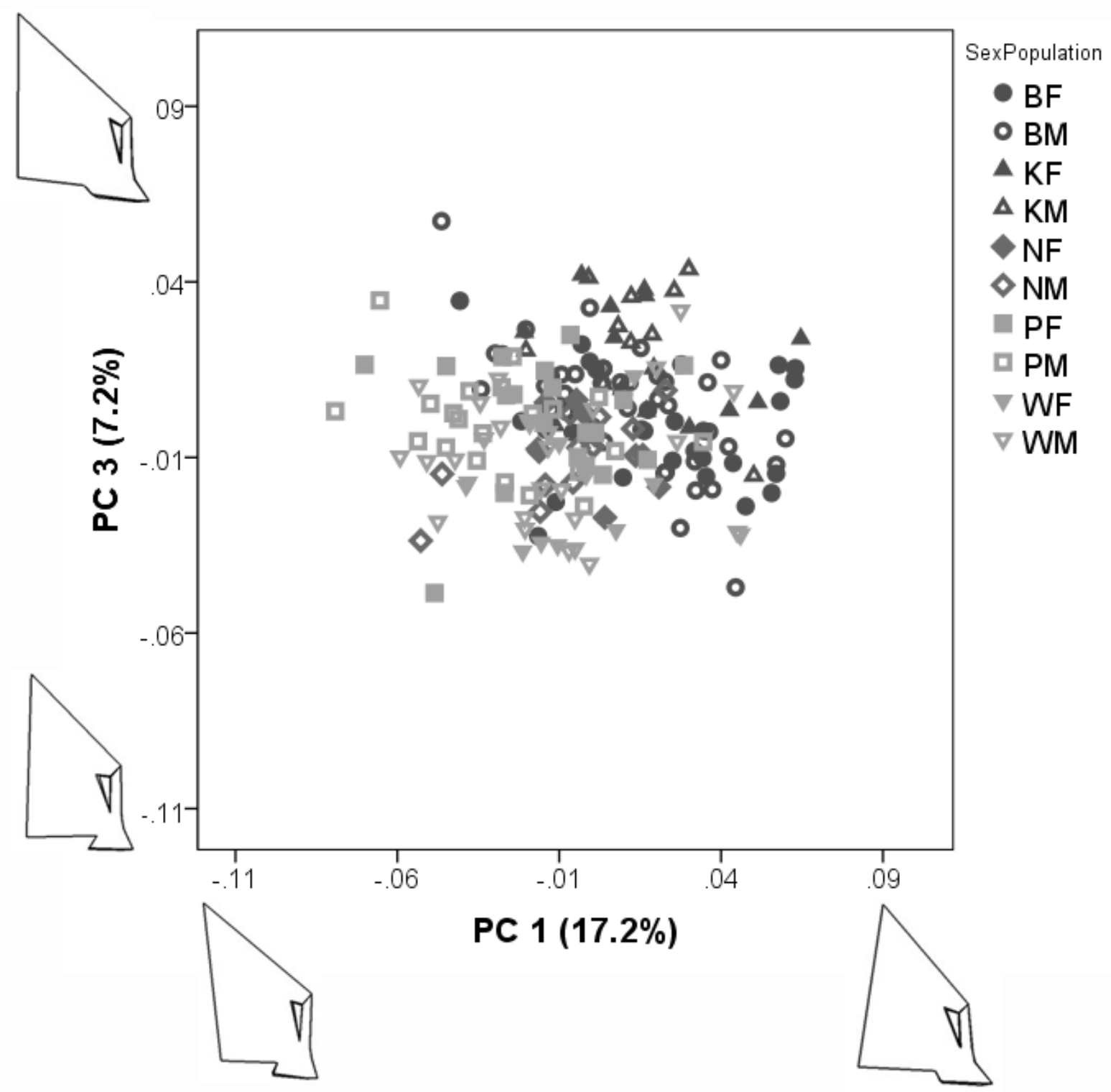


Figure 7.

* Intended to be reproduced in color on the Web (free of charge) and in black-and-white in print

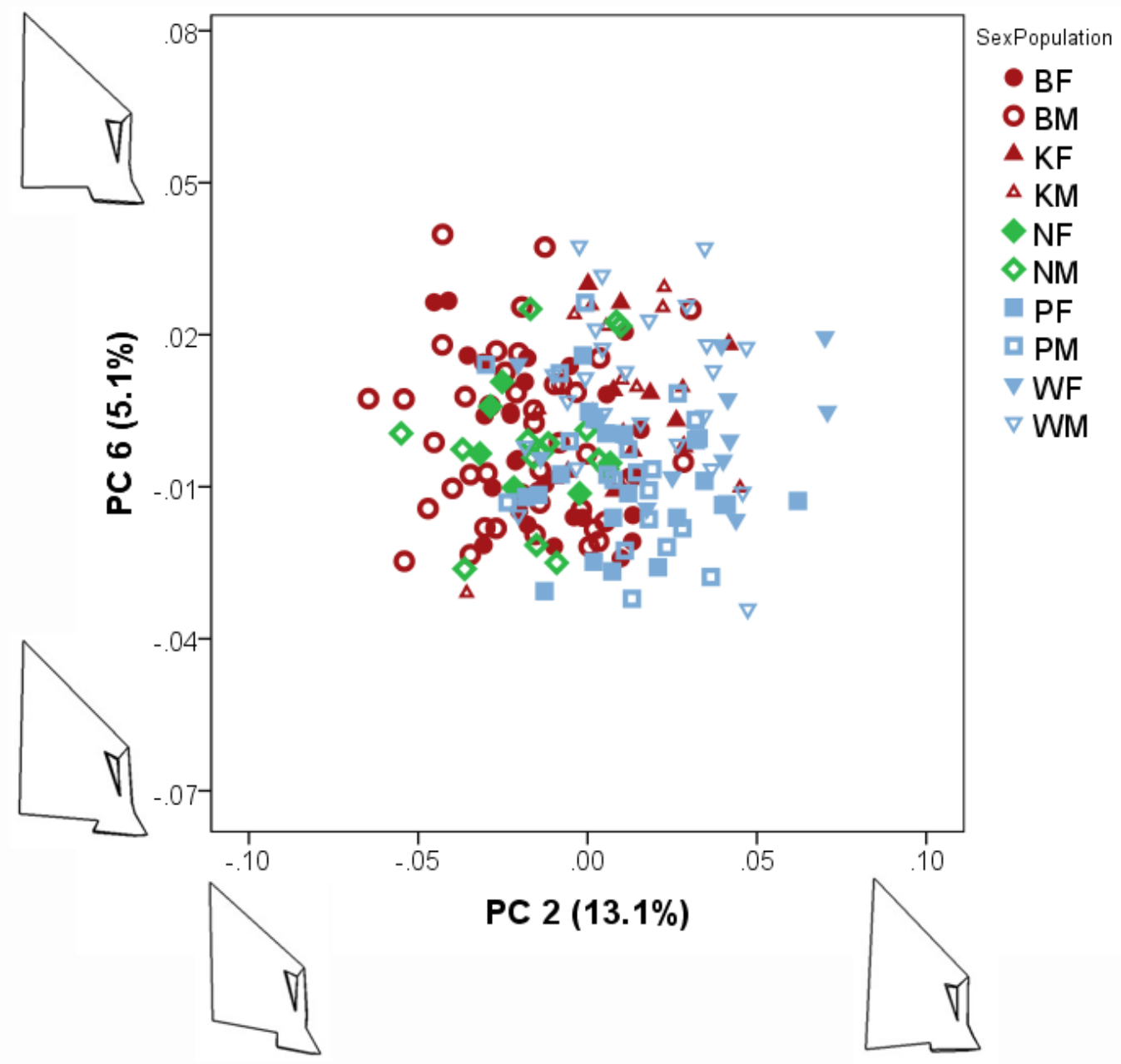




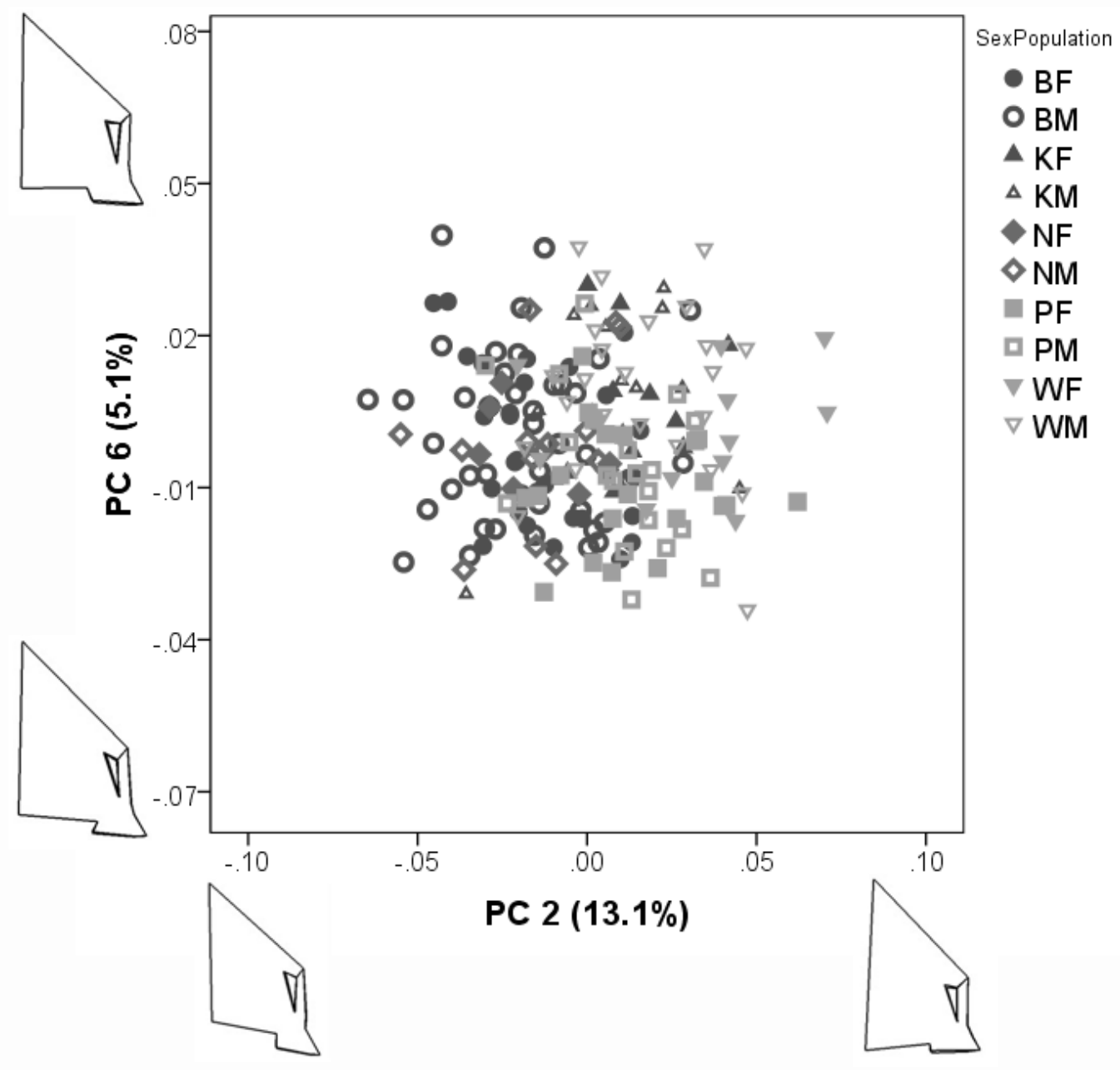


Figure 8.

(A)

(B)

$G I_{A}=\cos (\theta)$

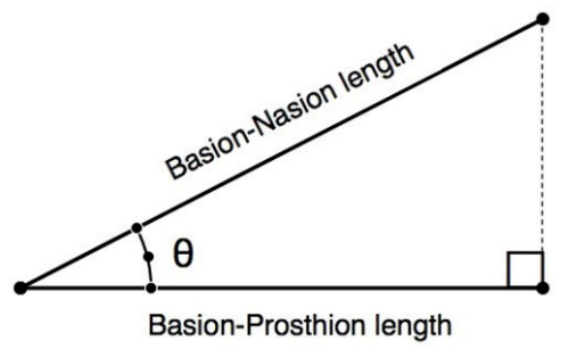

(C)

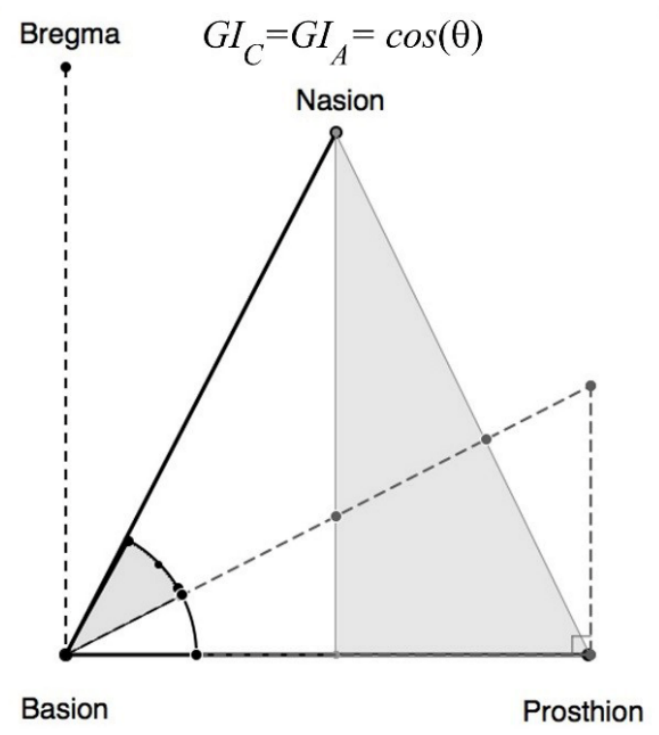

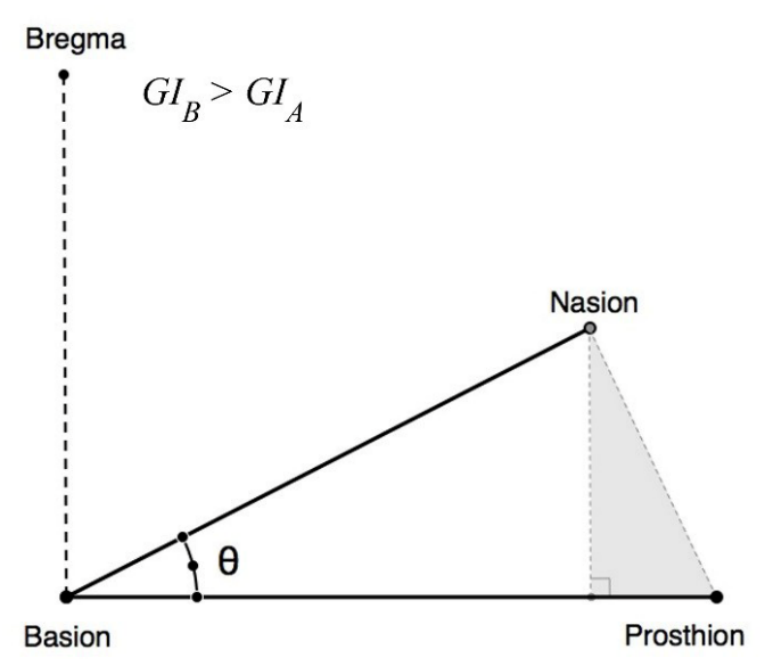

(D)

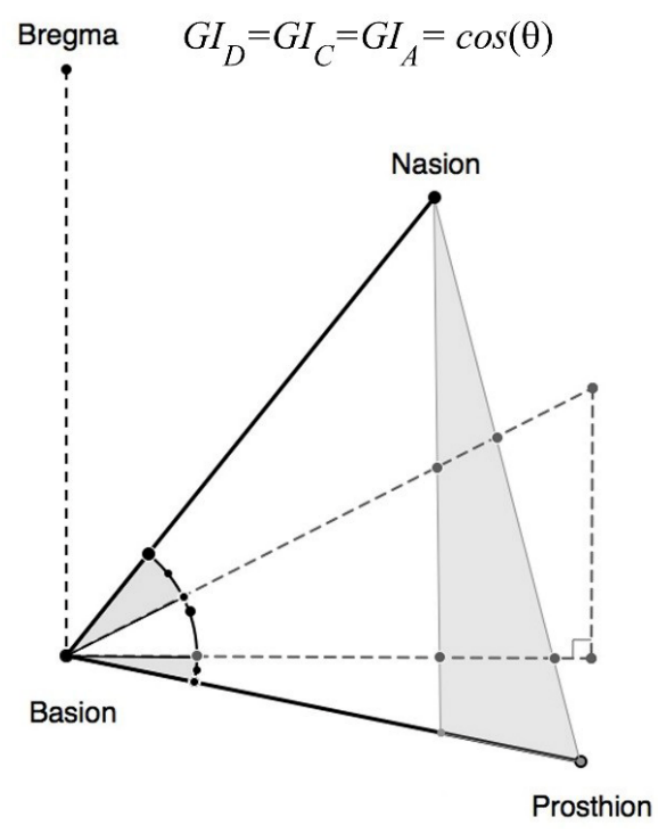

